NBER WORKING PAPER SERIES

\title{
MONETARY POLICY TRADE-OFFS IN AN ESTIMATED OPEN-ECONOMY DSGE MODEL
}

\author{
Malin Adolfson \\ Stefan Laséen \\ Jesper Lindé \\ Lars E.O. Svensson \\ Working Paper 14510 \\ http://www.nber.org/papers/w14510
}

\author{
NATIONAL BUREAU OF ECONOMIC RESEARCH \\ 1050 Massachusetts Avenue \\ Cambridge, MA 02138 \\ November 2008
}

All remaining errors are ours. The views, analysis, and conclusions in this paper are solely the responsibility of the authors and do not necessarily agree with the those of other members of the Riksbank staff or executive board, or other staff or members of the Board of Governors of the Federal Reserve System or of any other person associated with the Federal Reserve System, or of the National Bureau of Economic Research.

NBER working papers are circulated for discussion and comment purposes. They have not been peerreviewed or been subject to the review by the NBER Board of Directors that accompanies official NBER publications.

(C) 2008 by Malin Adolfson, Stefan Laséen, Jesper Lindé, and Lars E.O. Svensson. All rights reserved. Short sections of text, not to exceed two paragraphs, may be quoted without explicit permission provided that full credit, including $(\odot$ notice, is given to the source. 
Monetary Policy Trade-Offs in an Estimated Open-Economy DSGE Model

Malin Adolfson, Stefan Laséen, Jesper Lindé, and Lars E.O. Svensson

NBER Working Paper No. 14510

November 2008

JEL No. E52,E58,F33,F41

\section{ABSTRACT}

This paper studies the transmission of shocks and the trade-offs between stabilizing CPI inflation and alternative measures of the output gap in Ramses, the Riksbank's empirical dynamic stochastic general equilibrium (DSGE) model of a small open economy. The main results are, first, that the transmission of shocks depends substantially on the conduct of monetary policy, and second, that the trade-off between stabilizing CPI inflation and the output gap strongly depends on which concept of potential output in the output gap between output and potential output is used in the loss function. If potential output is defined as a smooth trend this trade-off is much more pronounced compared to the case when potential output is defined as the output level that would prevail if prices and wages were flexible.,

\author{
Malin Adolfson \\ Sveriges Riksbank \\ SE-103 37 Stockholm \\ Sweden \\ malin.adolfson@ riksbank.se \\ Stefan Laséen \\ Sveriges Riksbank \\ SE-103 37 Stockholm \\ Sweden \\ stefan.laseen@riksbank.se
}

\author{
Jesper Lindé \\ International Finance, mailstop 20 \\ Federal Reserve Board \\ 20th and $\mathrm{C}$ streets \\ Washington, NW \\ DC, 20551, USA \\ Jesper.L.Linde@frb.gov \\ Lars E.O. Svensson \\ Sveriges Riksbank \\ SE-103 37 Stockholm \\ Sweden \\ and NBER \\ svensson@princeton.edu
}




\section{Contents}

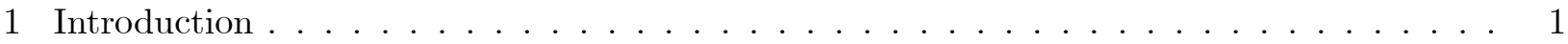

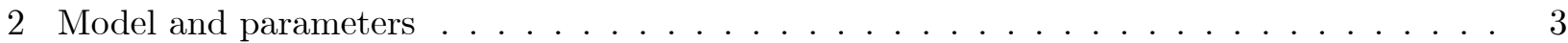

2.1 Model overview . . . . . . . . . . . . . . . . . . . . . 3

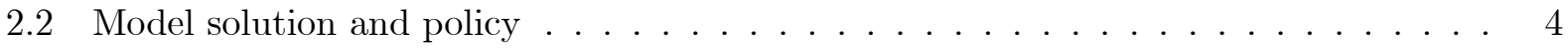

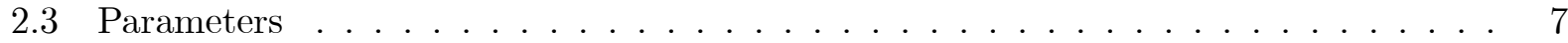

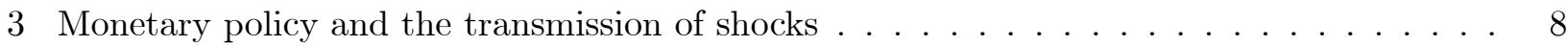

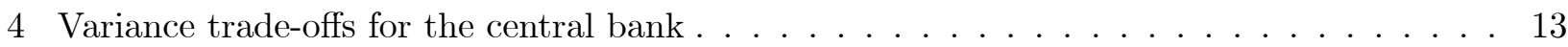

4.1 The zero lower bound on nominal interest rates . . . . . . . . . . . . . . . . 19

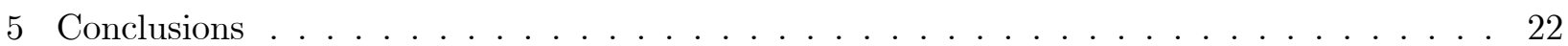

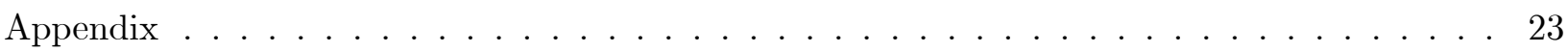

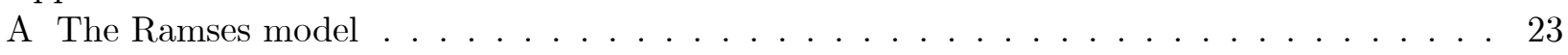

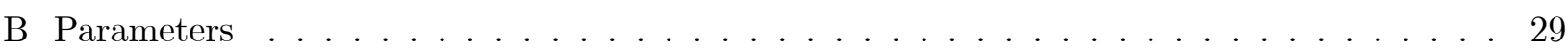

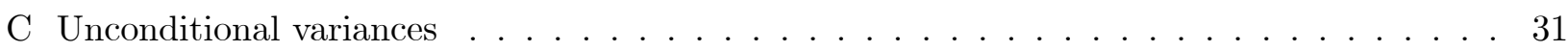




\section{Introduction}

In this paper we examine how different assumptions about the conduct of monetary policy affect the transmission of shocks in the economy. In addition, we also study the trade-off between stabilizing CPI inflation and alternative definitions of the output gap. We compare the transmission of shocks and variance trade-off under optimal monetary policy and under an estimated instrument rule using Ramses, the main model used at Sveriges Riksbank for forecasting and policy analysis. Ramses is a small open-economy dynamic stochastic general equilibrium (DSGE) model estimated with Bayesian techniques and is described in Adolfson, Laséen, Lindé, and Villani (ALLV) [4] and [5].

By optimal monetary policy we mean policy that minimizes an intertemporal loss function under commitment. We choose a quadratic loss function that corresponds to flexible inflation targeting and is the weighted sum of three terms: the squared inflation gap between 4-quarter CPI inflation and the inflation target, the squared output gap (measured as the deviation between output and potential output), and the squared quarterly change in the Riksbank's instrument rate, the repo rate. We compare the optimal policy with policy following an estimated instrument rule, to get an idea about how inefficient the empirically estimated rule is compared with optimal policy and about the policy preferences implied by the estimated rule.

The definition of potential output is important since this latent variable is used to compute the output gap (the difference between output and potential output) in the loss function. A conventional measure of potential output is a smooth trend, such as the result of a Hodrick-Prescott (HP) filter. A second definition of potential output, promoted in the recent academic literature, is defined as the level of output that would prevail if prices and wages were flexible, see for instance Woodford [20] and Gali [12]. This latter measure of potential output is in line with the work of Kydland and Prescott [14], since it incorporates efficient fluctuations of output due to technology shocks.

We first examine to what extent alternative monetary policy affects the transmission of various shocks in the economy. According to the estimated model, shocks to total factor productivity is a dominant driver of business cycles in Sweden (at least for policy under a simple instrument rule), why these are particularly interesting to study. The estimated model assigns a dominant role to productivity shocks in order to explain the fact that the correlation between GDP growth and CPI inflation is about -0.5 for the years 1950-2007. Productivity shocks have also been shown by ALLV [6] to play a key role for understanding the episode with low inflation and high output growth in Sweden 2003-2006. We therefore examine how monetary policy may affect the 
propagation of very persistent but stationary technology shocks. More specifically, we compare the impulse-response functions conditional on optimal policy and conditional on the estimated instrument rule. We find that monetary policy has an important role in the transmission of the technology shock into the economy. For instance, whether hours worked per capita rise or fall persistently depend on the weight on inflation stabilization relative to output-gap stabilization and interest-rate smoothing. Furthermore, the specification of potential output in the output-gap definition is important for the transmission of technology shocks. If potential output is defined as trend output, the output response after a technology shock will be substantially smaller than if potential output is specified as the level of output under flexible prices and wages. ${ }^{1}$ To illustrate the effects of a shock that creates a trade-off between inflation and output-gap stabilization regardless of which output-gap definition is used in the loss function we therefore also study the impulse responses to a labor supply shock.

We then examine the variance trade-off the central bank is facing under various specifications of the loss function, comparing the different output-gap definitions. Results for the estimated instrument rule are also reported. The efficient variance frontiers are computed with a given weight on interest-rate smoothing. As a benchmark, we use a weight of 0.37 on the squared changes in the nominal interest rate in the loss function. ${ }^{2}$ However, it turns out that the volatility of the nominal interest rate in this case heavily violates the zero lower bound (ZLB) of the interest rate. Therefore, we also follow the suggestion by Woodford [20] and Levine, Pearlman, and Yang [15] and investigate to what extent the efficient variance frontier is affected by increasing the weight on the squared interest rate in the loss function, in order to ensure a low probability of the nominal interest rate falling below zero. We also quantify to what extent the estimated instrument rule can be improved by optimizing the response coefficients of simple instrument rule to minimize the loss function. Finally, we examine how different sets of shocks (technology, markup, preference, and foreign shocks) affect the variance trade-offs faced by the central bank for different definitions of the output gap in the loss function.

Our main findings are as follows. First, the stationary productivity shocks create a sharp tradeoff between stabilizing CPI inflation and stabilizing the output gap when trend output is computed

\footnotetext{
1 Potential output under flexible prices/wages is defined as the output level that would result if prices and wages are completely flexible but real distortions remain. We compare both unconditional and conditional potential output. Conditional potential output is contingent upon the existing current predetermined variables, whereas unconditional potential output is computed assuming the flexible price equilibrium has lasted forever, thus making use of a hypothetical level of the predetermined variables (see Adolfson, Laséen, Lindé and Svensson (ALLS) [2] for a detailed discussion).

2 This number stems from estimating the model on Swedish data under the assumption that the Riksbank conducted monetary policy according to the loss function with the trend output gap, see ALLS [2].
} 
with a smooth trend. Second, using an output gap in the loss function where potential output is defined as the level of output under flexible prices and wages improves the policy trade-off, but the trade-off still remains significant, in particular for labor supply shocks (which are isomorphic to wage markup shocks) and price markup shocks. Third, the estimated instrument rule is clearly inefficient relative to the optimal policy. Most of this ineffectiveness is driven by the fact that the estimated policy rule responds very inefficiently to fluctuations induced by foreign shocks. Fourth, optimizing the coefficients in the simple instrument rule closes about half the distance relative to the optimal policy. Finally, imposing the ZLB constraint for the nominal interest rate shifts out the variance frontiers somewhat, but the conclusions regarding the trend output gap and the flexible price-wage output gap are robust to introducing this constraint.

The outline of the paper is as follows: Section 2 presents the model and very briefly discusses the data and the estimation of the model. Section 3 discusses the impulse responses to a stationary technology shock and a labor supply shock and their dependency on the policy assumption made. Section 4 illustrates the variance trade-offs the central bank is facing under different output-gap definitions. Finally, section 5 presents a summary and some conclusions. An appendix contains some technical details. More technical details are reported in Adolfson, Laséen, Lindé and Svensson (ALLS) [3].

\section{Model and parameters}

\subsection{Model overview}

This section gives an overview of the model economy. In appendix A the theoretical model is described in greater detail. ${ }^{3}$

The model is an open-economy DSGE model similar to the one developed in ALLV [4] and shares its basic closed economy features with many recent new Keynesian models, including the benchmark models of Christiano, Eichenbaum and Evans [9], Altig, Christiano, Eichenbaum and Lindé [7], and Smets and Wouters [18].

The model economy consists of households, domestic-goods firms, importing consumption and investment firms, exporting firms, a government, a central bank, and an exogenous foreign economy. The households consume a basket consisting of domestically produced goods and imported goods, which are supplied by domestic and importing firms, respectively. We allow the imported goods to

\footnotetext{
${ }^{3}$ For a complete list of the log-linearized equations in the model we refer to ALLS [2].
} 
enter both aggregate consumption as well as aggregate investment. This is needed to match the joint fluctuations in both imports and consumption since imports (and investment) are much more volatile than consumption.

Households can invest in their stock of capital, save in domestic bonds and/or foreign bonds, and hold cash. The choice between domestic and foreign bonds results in an arbitrage condition pinning down expected exchange-rate changes (that is, an uncovered interest parity condition). Compared with a standard setting, the risk premium is allowed to be negatively correlated with the expected change in the exchange rate, following the evidence discussed in for example Duarte and Stockman [11]. As in the closed-economy model households rent capital to the domestic firms and decide how much to invest in the capital stock given costs of adjusting the investment rate. Wage stickiness is introduced through an indexation variant of the Calvo [8] model.

Domestic production is exposed to stochastic technology growth as in Altig, Christiano, Eichenbaum, and Lindé [7]. The firms (domestic, importing and exporting) all produce differentiated goods and set prices according to an indexation variant of the Calvo model. By including nominal rigidities in the importing and exporting sectors we allow for short-run incomplete exchange rate pass-through to both import and export prices.

The conduct of monetary policy is approximated with either a Taylor-type instrument rule or optimal policy minimizing a loss function (see further details in section 2.2). When we estimate the model, we allow for different monetary policy conduct before and after the Swedish adoption of an inflation targeting regime (see section 2.3 and appendix A).

The model adopts a small open-economy perspective where we assume that the foreign economy is exogenous. The foreign inflation, output and interest rate are therefore given by an exogenous VAR. In what follows we describe the behavior of the central bank.

\subsection{Model solution and policy}

After log-linearization, Ramses is a log-linear model with forward-looking variables. It can be written in the following state-space form,

$$
\left[\begin{array}{c}
X_{t+1} \\
H x_{t+1 \mid t}
\end{array}\right]=A\left[\begin{array}{c}
X_{t} \\
x_{t}
\end{array}\right]+B i_{t}+\left[\begin{array}{c}
C \\
0
\end{array}\right] \varepsilon_{t+1}
$$

Here, $X_{t}$ is an $n_{X}$-vector of predetermined variables in period $t$ (where the period is a quarter); $x_{t}$ is an $n_{x}$-vector of forward-looking variables; $i_{t}$ is an $n_{i}$-vector of instruments (the forward- 
looking variables and the instruments are the nonpredetermined variables) $;{ }^{4} \varepsilon_{t}$ is an $n_{\varepsilon}$-vector of i.i.d. shocks with mean zero and covariance matrix $I_{n_{\varepsilon}} ; A, B$, and $C$, and $H$ are matrices of the appropriate dimension; and $y_{t+\tau \mid t}$ denotes $\mathrm{E}_{t} y_{t+\tau}$ for any variable $y_{t}$, the rational expectation of $y_{t+\tau}$ conditional on information available in period $t$. The variables are measured as differences from steady-state values, so their unconditional means are zero. The elements of the matrices $A$, $B, C$, and $H$ are estimated with Bayesian methods and considered fixed and known for the policy simulations. Hence the conditions for certainty equivalence are satisfied. The appendix of ALLS [2] provides details on Ramses, including the elements of the vectors $X_{t}, x_{t}, i_{t}$, and $\varepsilon_{t}$.

First we assume monetary policy can be described as minimizing an intertemporal loss function under commitment. Let $Y_{t}$ be an $n_{Y}$-vector of target variables, measured as the difference from an

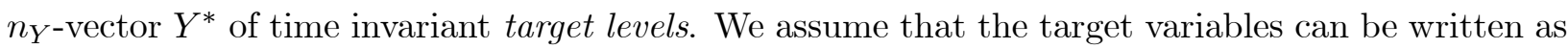
a linear function of the predetermined, forward-looking, and instrument variables,

$$
Y_{t}=D\left[\begin{array}{c}
X_{t} \\
x_{t} \\
i_{t}
\end{array}\right] \equiv\left[\begin{array}{lll}
D_{X} & D_{x} & D_{i}
\end{array}\right]\left[\begin{array}{c}
X_{t} \\
x_{t} \\
i_{t}
\end{array}\right],
$$

where $D$ is an $n_{Y} \times\left(n_{X}+n_{x}+n_{i}\right)$ matrix and partitioned conformably with $X_{t}, x_{t}$, and $i_{t}$. Let the intertemporal loss function in period $t$ be

$$
\mathrm{E}_{t} \sum_{\tau=0}^{\infty} \delta^{\tau} L_{t+\tau}
$$

where $0<\delta<1$ is a discount factor, $L_{t}$ is the period loss given by

$$
L_{t} \equiv Y_{t}^{\prime} W Y_{t}
$$

and $W$ is a symmetric positive semidefinite matrix.

We consider the following target variables: the model-consistent 4-quarter CPI inflation rate, $p_{t}^{c}-p_{t-4}^{c}$, where $p_{t}^{c}$ denotes the log of the CPI; a measure of the output gap, $y_{t}-\bar{y}_{t}$, where $y_{t}$ denotes output and $\bar{y}_{t}$ denotes potential output; and the first difference of the instrument rate, $i_{t}-i_{t-1}$, where $i_{t}$ denotes the Riksbank's instrument rate, the repo rate. The period loss is

$$
L_{t}=\left(p_{t}^{c}-p_{t-4}^{c}-\pi^{*}\right)^{2}+\lambda_{y}\left(y_{t}-\bar{y}_{t}\right)^{2}+\lambda_{\Delta i}\left(i_{t}-i_{t-1}\right)^{2},
$$

where $\pi^{*}$ is the $2 \%$ inflation target and $\lambda_{y}$ and $\lambda_{\Delta i}$ are nonnegative weights on output-gap stabilization and instrument-rate smoothing, respectively. That is, the vector of target variables is $Y_{t} \equiv\left(p_{t}^{c}-p_{t-4}^{c}-\pi^{*}, y_{t}-\bar{y}_{t}, i_{t}-i_{t-1}\right)^{\prime}$ and the matrix $W$ is the matrix with diagonal $\left(1, \lambda_{y}, \lambda_{\Delta i}\right)^{\prime}$.

\footnotetext{
${ }^{4}$ A variable is predetermined if its one-period-ahead prediction error is an exogenous stochastic process (Klein [13]). For $(2.1)$, the one-period-ahead prediction error of the predetermined variables is the stochastic vector $C \varepsilon_{t+1}$.
} 
We use 4-quarter inflation as a target variable rather than quarterly inflation, since the Riksbank and other inflation-targeting central banks normally specify their inflation target as a 12-month rate. Furthermore, the inflation target variable is assumed to be model-consistent CPI inflation since this measure more accurately captures the true import content in the consumption basket. ${ }^{5}$

Under the assumption of optimization under commitment in a timeless perspective, the optimal policy and resulting equilibrium can be described by the following difference equations,

$$
\begin{aligned}
{\left[\begin{array}{c}
x_{t} \\
i_{t}
\end{array}\right] } & =F\left[\begin{array}{c}
X_{t} \\
\Xi_{t-1}
\end{array}\right] \\
{\left[\begin{array}{c}
X_{t+1} \\
\Xi_{t}
\end{array}\right] } & =M\left[\begin{array}{c}
X_{t} \\
\Xi_{t-1}
\end{array}\right]+\left[\begin{array}{c}
C \\
0
\end{array}\right] \varepsilon_{t+1},
\end{aligned}
$$

for $t \geq 0$, where $X_{0}$ and $\Xi_{-1}$ are given. The Klein algorithm returns the matrices $F$ and $M$. These matrices depend on $A, B, H, D, W$, and $\delta$, but they are independent of $C$. The independence of $C$ demonstrates the certainty equivalence of the optimal policy and equilibrium. The $n_{X}$-vector $\Xi_{t}$ consists of the Lagrange multipliers of the lower block of (2.1), the block determining the forwardlooking variables. The initial value $\Xi_{-1}$ for $t=0$ is given by the optimization for $t=-1$ (or equal to zero in the case of commitment from scratch in $t=0$ ). The choice and calculation of the initial $\Xi_{-1}$ is further discussed in ALLS [2].

We compare results from three different specifications of the output gap $\left(y_{t}-\bar{y}_{t}\right)$ in the loss function. The first definition, the trend output gap uses the trend production level as potential output $\left(\bar{y}_{t}\right)$, which is growing stochastically due to the unit-root stochastic technology shock in the model. This definition of potential output will resemble a potential output computed with an HP filter. ${ }^{6}$ The second definition, the unconditional output gap, specifies potential output as the hypothetical output level that would arise if prices and wages were completely flexible and had been so for a very long time. Unconditional potential output therefore presumes different levels of the predetermined variables, including the capital stock, from those in the actual economy. In contrast, the third definition, the conditional output gap, makes potential output contingent upon the existing current predetermined variables. Conditional potential output is thus defined as the

\footnotetext{
${ }^{5}$ In the model, where total consumption is a CES function of imported and domestic goods, model-consistent CPI inflation is

$$
p_{t}^{c, \text { model }}-p_{t-4}^{c, \text { model }}=\left(1-\omega_{c}\right)\left(p^{c} / p^{d}\right)^{-\left(1-\eta_{c}\right)}\left(p_{t}^{d}-p_{t-4}^{d}\right)+\omega_{c}\left(p^{c} / p^{m, c}\right)^{-\left(1-\eta_{c}\right)}\left(p_{t}^{m, c}-p_{t-4}^{m, c}\right),
$$

where $\omega_{c}$ is the share of expenditures in the CPI spent on imported goods, $p_{t}^{d}$ the $(\log )$ domestic price level and $p_{t}^{m, c}$ the $(\log )$ price of imported goods that the consumer has to pay. The weights used to calculate the modelconsistent inflation differ from those in the data by the steady-state relative prices $\left(p^{c} / p^{d}\right.$ and $\left.p^{c} / p^{m, c}\right)$, which lower the import share in consumption. This definition of CPI inflation is consequently consistent with the notion that due to distribution costs etc., the import share of consumption is somewhat exaggerated in the official statistics.

${ }^{6}$ The correlation between the trend output gap and an output gap computed with the HP-filter is about 0.65 using 5000 observations of simulated data from the model.
} 
hypothetical output level that would arise if prices and wages suddenly become flexible in the current period and are expected to remain flexible in the future. ${ }^{7}$

We define the flexprice equilibrium under the assumption that prices and wages are completely flexible in the domestic economy (thus keeping the foreign economy distorted), and determine the nominal variables by assuming that CPI inflation is kept constant at its steady-state level $\left(\hat{\pi}_{t}^{c}=0\right)$. When computing the two cases of flexprice potential output we also disregard markup shocks and fiscal shocks, and set these to zero in the flexprice economy.

Lastly, as a comparison to the optimal policy under equation (2.5), we also include the estimated instrument rule in the subsequent analysis. In this case monetary policy is approximated with a generalized Taylor-type instrument rule, following Smets and Wouters [18]. The central bank is assumed to adjust the short term interest rate in response to deviations of CPI inflation from a time-varying inflation target, the output gap (measured as actual minus trend output), the real exchange rate and the interest rate set in the previous period. The instrument rule (expressed in log-linearized terms) follows:

$$
\begin{aligned}
i_{t}= & \rho_{R t} i_{t-1}+\left(1-\rho_{R t}\right)\left[\bar{\pi}_{t}^{c}+r_{\pi t}\left(p_{t}^{c}-p_{t-1}^{c}-\bar{\pi}_{t}^{c}\right)+r_{y t}\left(y_{t-1}-\bar{y}_{t-1}\right)+r_{x t} \widehat{\tilde{x}}_{t-1}\right] \\
& +r_{\Delta \pi, t} \Delta\left(p_{t}^{c}-p_{t-1}^{c}\right)+r_{\Delta y, t} \Delta\left(y_{t}-\bar{y}_{t}\right)+\varepsilon_{R t},
\end{aligned}
$$

where $i_{t}$ denotes the Riksbank's repo rate, $\Delta$ denotes the first-difference operator, $\bar{\pi}_{t}^{c}$ denotes a time-varying inflation target, $\widehat{\tilde{x}}_{t} \equiv \hat{S}_{t}+\hat{P}_{t}^{*}-\hat{P}_{t}^{c}$ denotes the real exchange rate (log-deviations from steady-state are denoted by a hat), $S_{t}$ denotes the nominal exchange rate, $P_{t}^{*}$ denotes the foreign price level, and $\varepsilon_{R t}$ is an uncorrelated monetary-policy shock.

\subsection{Parameters}

The model's parameters are estimated using Bayesian techniques on 15 Swedish macroeconomic variables during the period 1980Q1-2007Q3. We refer the reader to ALLS [2] for a detailed description of the estimation. To make the paper self-contained we report in appendix B the values for the calibrated parameters (table B.1) and the obtained estimation results (table B.2). In the subsequent analysis the estimated posterior mode values under the estimated instrument rule are used for all the non-policy parameters. The estimates of the model parameters seem invariant with respect to alternative assumptions about monetary policy during the sample we use to estimate

\footnotetext{
${ }^{7}$ For a detailed description on how to calculate the unconditional and conditional potential output, see appendix $\mathrm{C}$ in ALLS [2].
} 
the model, so we treat them as structural and independent of the monetary policy. ${ }^{8}$

\section{Monetary policy and the transmission of shocks}

Under optimal policy, the central bank responds to all relevant predetermined variables and shocks to the economy. With a simple instrument rule, the central bank only responds to some variables of the economy. To understand how monetary policy affects the dynamics of the model, we first look at the impulse response functions to a stationary technology shock under optimal policy and under policy with the estimated instrument rule, since total factor productivity is a key driver of business cycles in according to the estimated model.

Figure 3.1 depicts the impulse responses to a positive stationary technology shock (one standard deviation) for optimal policy and for policy with the estimated instrument rule. The impulse occurs in quarter 0 . Before quarter 0 , the economy is in the steady state with $X_{t}=0$ and $\Xi_{t-1}=0$ for $t \leq 0$ and $x_{t}=0$ and $i_{t}=0$ for $t \leq-1$. Under optimal policy, we use the estimated loss function $\left(\lambda_{y}=1.10, \lambda_{\Delta i}=0.37\right.$ ) with the trend output gap (where the output gap between output and trend production is used), the unconditional output gap (the gap between output and unconditional flexprice potential output), and the conditional output gap (the gap between output and conditional flexprice potential output) and plot the corresponding impulse responses. It should be noted that this technology shock does not affect trend output in the model (which is influenced only by the unit-root technology shock). The output level under flexible prices and wages, flexprice potential output, is of course affected by the shock.

We start by comparing the impulse responses under policies using the trend output gap either as a response variable (instrument rule) or as a target variable in the loss function (optimal policy). Even if the instrument-rule parameters and the loss-function parameters are both estimated to capture the historical behavior of the central bank, the responses to a stationary technology shock are quite different when following the instrument rule (dashed curves) or using the quadratic loss function (dashed-dotted curves). The figure shows that optimal policy stabilizes inflation and the output gap more effectively over time than the instrument rule, although optimal policy initially allows a larger fall of both CPI and domestic inflation when using the trend output gap in its loss function. The nominal interest-rate response under the instrument rule is much more persistent

\footnotetext{
${ }^{8}$ In particular, in ALLS [2] we estimate the model under two assumptions regarding the conduct of monetary policy during the inflation targeting period (1993-). First, we approximate monetary policy with the simple Taylortype rule (2.9), and second we approximate it with loss function of the type (2.5). In both cases, we obtain very similar parameter estimates.
} 
Figure 3.1: Impulse response functions to a (one-standard deviation) stationary technology shock under optimal policy for different output gaps and under the estimated instrument rule.
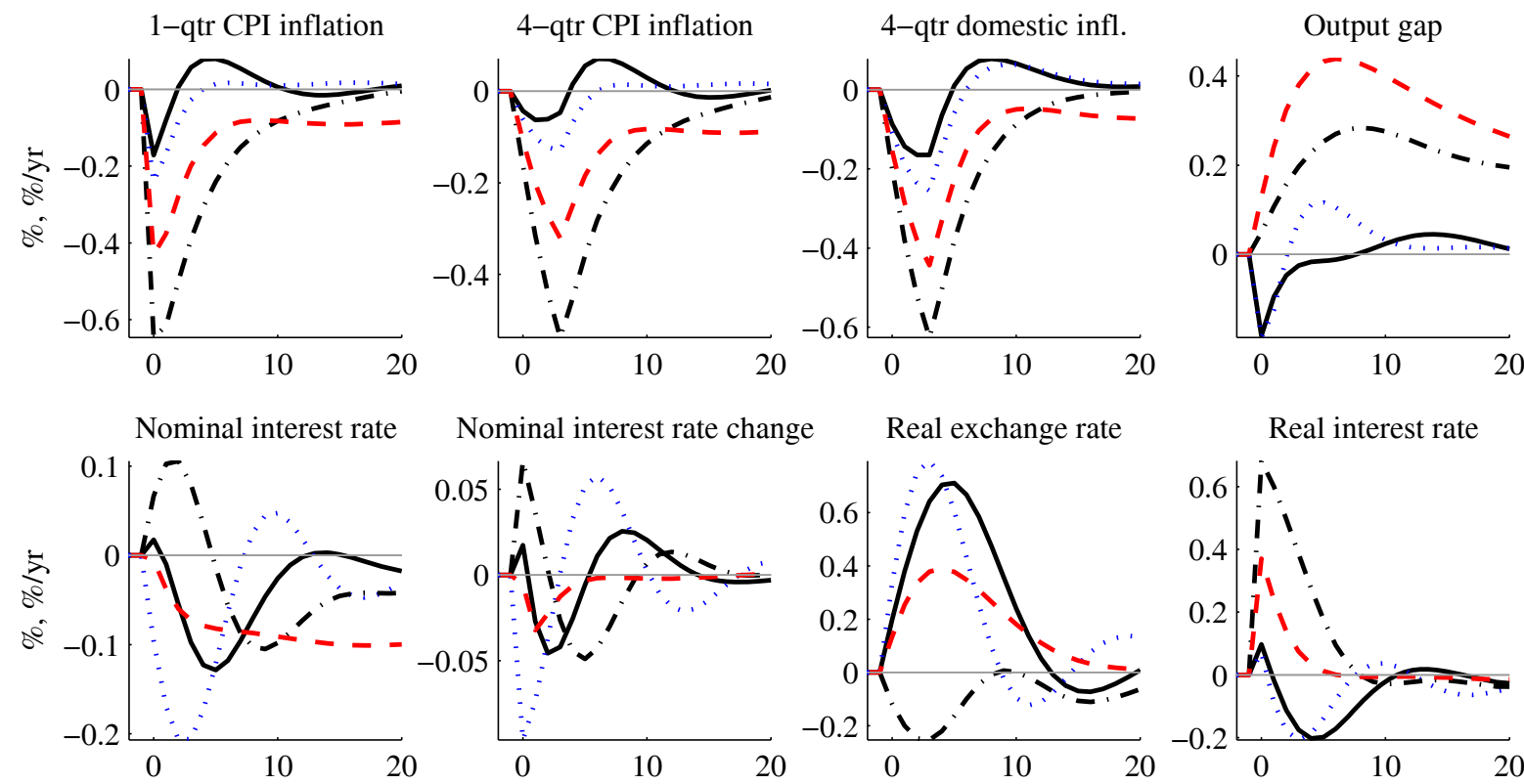

Nominal interest rate change
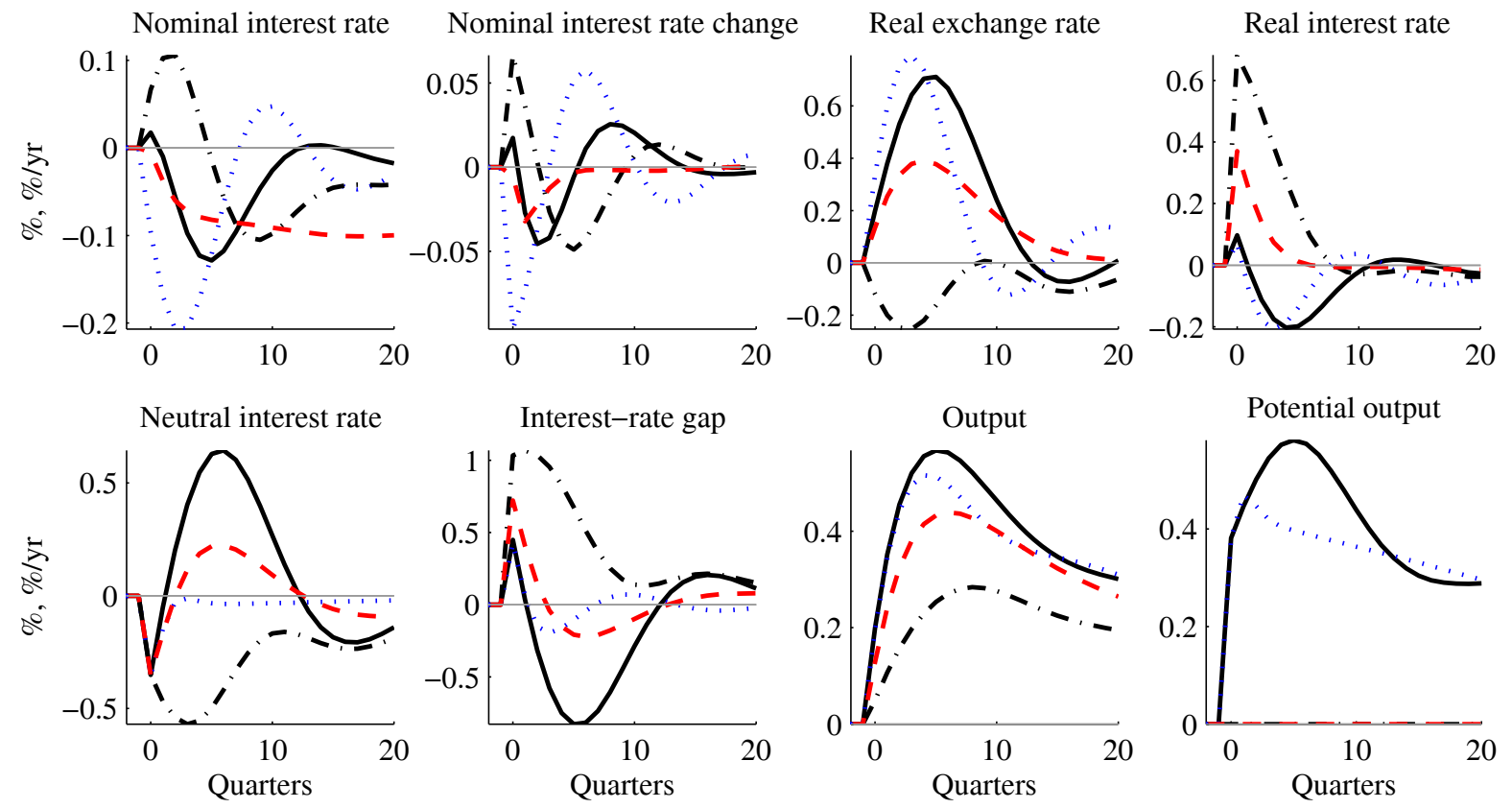

— Conditional $\ldots \ldots$ Unconditional $\cdot$ - $\cdot$ - Trend - - - Instrument rule

than under optimal policy (which is even of the opposite sign), but inflation can still not be brought back to target as quickly. The real interest-rate response (level as well as the gap between the real interest rate and the state-dependent neutral real interest rate) is almost twice as high under optimal policy compared with the instrument rule and therefore reduces the increase in the trend output gap relative to the instrument rule. The stationary technology shock creates a trade-off for the central bank between balancing the induced decline in inflation and the higher (trend) output gap, and since the shock process is very persistent $\left(\rho_{\varepsilon}=0.966\right)$ this trade-off will last for many quarters. Under optimal policy such a trade-off is very costly in terms of the loss function, so the central bank invokes a forceful response to the technology shock. In contrast, the instrument rule 
cannot respond in an optimal fashion for each shock separately, but captures a realistic response based on inflation and the trend output gap derived from the historical behavior of the central bank. Had the central bank used larger (lower) coefficients on the inflation (trend output gap) variables in the instrument rule relative to the empirical estimates, inflation would approach target much faster after a shock to technology also under the instrument rule.

Figure 3.1 also illustrates the differences because of alternative output-gap measures in the central bank's loss function. The solid and dotted curves show the impulse responses under optimal policy when potential output is specified as the output level prevailing under completely flexible prices and wages, where the flexprice equilibrium has lasted forever (unconditional flexprice potential output, dotted) or where prices and wages become flexible in the current period (conditional flexprice potential output, solid). The dashed-dotted curves, on the other hand, show the impulses when the central bank stabilizes deviations of output from trend potential output. Due to sticky prices and wages, the stationary technology shock affects (unconditional/conditional) potential output quicker than actual output, and the flexprice output gap is therefore initially negative, whereas the trend output gap is positive (since trend output is by definition not affected by the shock). This important difference between the two output-gap definitions implies that the interest rate responses differ. The real interest rate response is negative when the central bank stabilizes the flexprice output gap and positive when it stabilizes the trend output gap. When the central bank stabilizes the flexprice output gap, it does not face the unfavorable trade-off between stabilizing inflation and the trend output gap. Therefore, the policy response can almost solely be directed at keeping inflation at target. This in effect implies that inflation can be stabilized much quicker than for the trend output gap, even though the weights in the loss function are the same in the two cases.

Another result from figure 3.1 is that the impulse responses of conditional and unconditional potential output differ. This is so because conditional potential output depends on the existing level of the predetermined variables in the actual economy with sticky prices and wages whereas unconditional potential output depends on the hypothetical level of the predetermined variables of the hypothetical economy with flexible prices and wages. When the shock hits the economy in quarter 0 , the two output-gap definitions will be equal (since the economy by assumption starts out in steady state in quarter -1 , which is the same for both the actual economy and the hypothetical flexprice economy), but in quarter 1 they will diverge. This is because conditional potential output in period 1 depends on the actual level of the predetermined variables in quarter 1 in the economy 
with sticky prices and wages whereas unconditional potential output in quarter 1 depends on the hypothetical level of the predetermined variables in quarter if prices and wages had been flexible (see appendix C in ALLS [2] for further details). The predetermined variables in quarter 1 in the sticky-price economy will differ from those in the flexprice economy because the forward-looking variables and the instrument rate in quarter 0 will differ between the sticky-price and the flexprice economy. Even if no new innovations have occurred between quarter 0 and quarter $t$, the levels of the predetermined variables used for computing the two potential output levels will thus differ. Since actual output and conditional potential output share the same predetermined variables in each period, the conditional output gap will normally be smaller than the the unconditional output gap. Moreover, with different output gaps in the loss function, the optimal policy responses will normally be different.

In figure 3.2 we show how sensitive the impulse responses to a stationary technology shock are to changes in the weight on output stabilization and interest-rate smoothing when using the unconditional output gap in the loss function. The solid curve (a) reiterates the optimal responses under the estimated loss function $\left(\lambda_{y}=1.10, \lambda_{\Delta i}=0.37\right)$, which is compared with (b) strict CPI inflation targeting $\left(\lambda_{y}=0, \lambda_{\Delta i}=0.01\right.$, dotted $)$, (c) more output stabilization $\left(\lambda_{y}=5\right.$, $\lambda_{\Delta i}=0.37$, dashed-dotted), and (d) more interest-rate smoothing and less output stabilization $\left(\lambda_{y}=0, \lambda_{\Delta i}=2.0\right.$, dashed).

For strict inflation targeting, (b), the central bank stabilize inflation after the technology shock almost completely, but with high variability in the real variables and the nominal interest rate. For some weight on interest-rate smoothing, (d), the nominal interest rate response is substantially moderated, at the cost of more inflation variability. Finally, for a higher weight on stabilizing the output gap, (c), the output gap response is moderated relative to the other cases.

To illustrate the effects of a shock that creates a trade-off between inflation and output-gap stabilization irrespective of which definition of output gap is used in the loss function, figure 3.3 shows the impulse responses to a negative (one standard deviation) labor supply shock. In the theoretical model, this shock is up to a scaling factor observationally equivalent to a (positive) wage markup shock. This shock induces a negative output gap both measured as deviation from trend potential output as well as from (conditional and unconditional) flexprice potential output. Trend potential output is not at all affected by the stationary wage markup shock, whereas (conditional and unconditional) flexprice potential output is. Because of wage and price stickiness, actual output is not directly adjusted to the disturbance. The higher real wage (not shown) pushes down 
Figure 3.2: Impulse response functions to a (one-standard deviation) stationary technology shock for different weights in the loss function with the unconditional output gap.
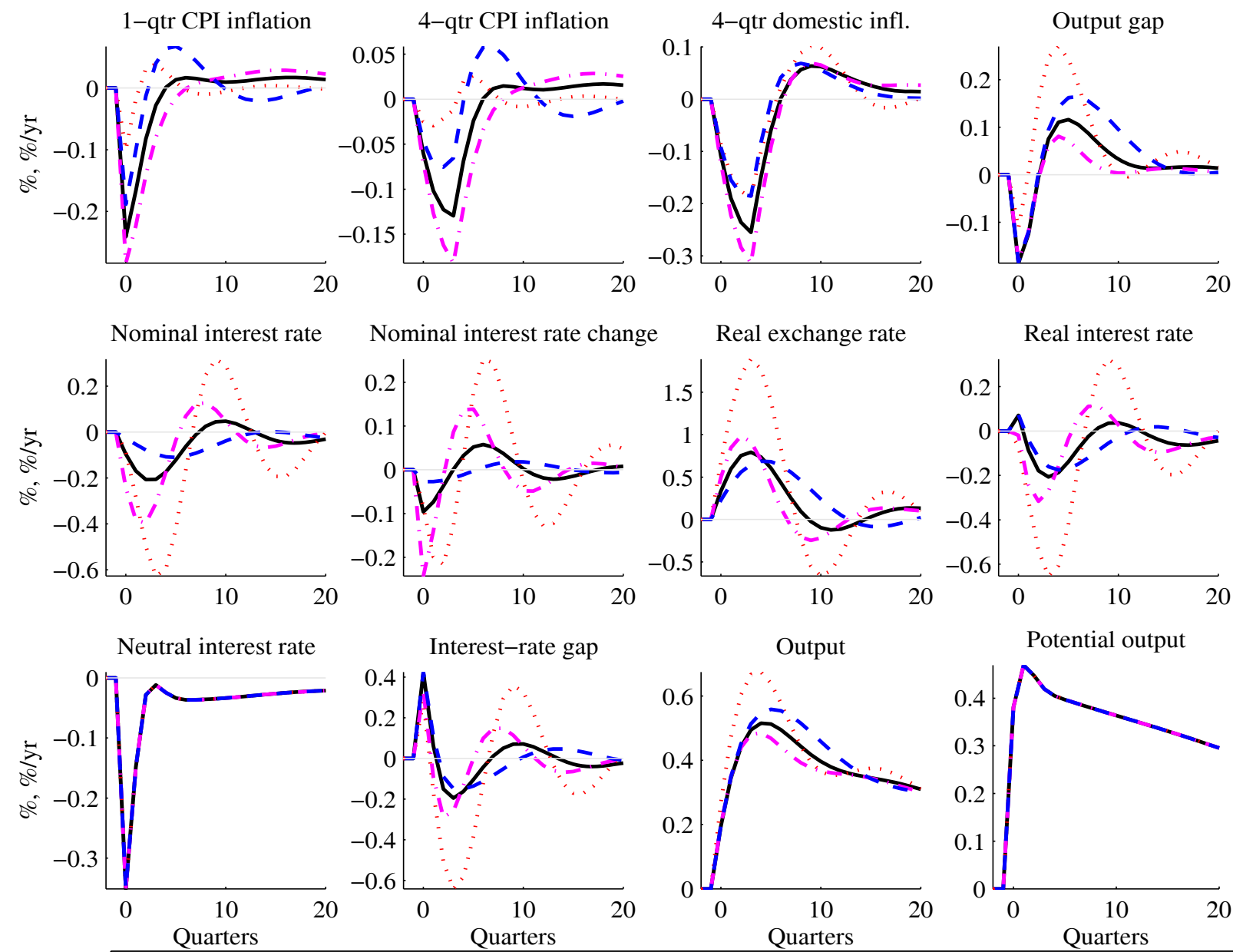

Potential output

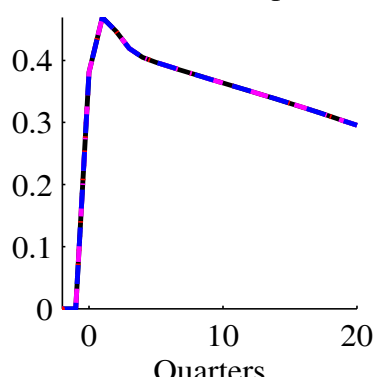

(a) $\lambda_{y}=1.1, \lambda_{\Delta i}=0.37$

(b) $\lambda_{y}=0, \lambda_{\Delta i}=0.01$

- (c) $\lambda_{y}=5, \lambda_{\Delta i}=0.37$

(d) $\lambda_{y}=0, \lambda_{\Delta i}=2$

hours worked (not shown) and thereby both potential and actual output. However, under flexible wages, the real wage and hours worked adjusts very quickly to the new state, which feeds into unconditional flexprice potential output and generates a negative output gap. The effects on the real wage, flexprice potential output and actual output are more short-lived compared with the technology shock, since the persistence of the labor supply shock is much lower $\left(\rho_{\varsigma_{h}}=0.38\right)$. However, as seen from the unconditional output gap (which is not closed as quickly), the dynamic differences under the labor supply shock are larger compared with the technology shock. We also see that after a labor supply shock, the instrument rule is about as good as optimal policy, either with trend or unconditional output gap in the loss function, in bringing inflation back to target. With 
Figure 3.3: Impulse response functions to a (one-standard deviation) labor supply shock under optimal policy for different output gaps and under the instrument rule.
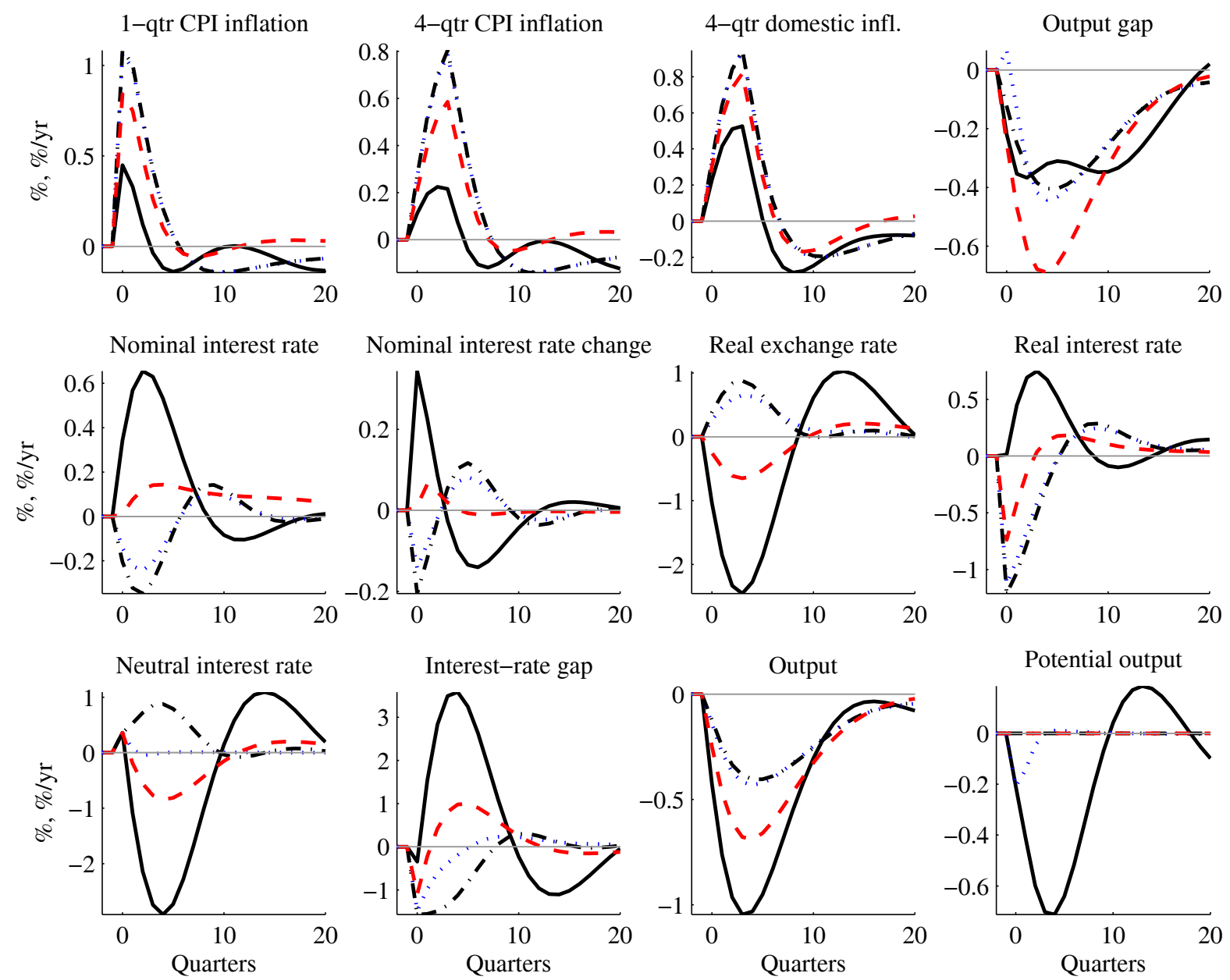

— Conditional $\ldots \ldots$ Unconditional $\cdot$ - $\cdot$ - Trend - - - Instrument rule

the conditional output gap in the loss function, it appears that inflation is stabilized more for the given weights in the loss function. Since conditional flexprice potential output is contingent upon the current state variables it resembles actual output more than unconditional flexprice potential output (cf. the solid curves), implying a somewhat smaller output gap and thereby more scope for inflation stabilization when the weights in the loss function are identical.

\section{Variance trade-offs for the central bank}

In this section, we examine the trade-offs the central bank is facing under optimal policy and under a simple instrument rule. As shown in Rudebusch and Svensson [16], when the intertemporal 
loss function (2.3) is scaled by $1-\delta$, the expected (conditional) intertemporal loss becomes equal to the unconditional mean of the period loss function when the discount factor approaches unity $\left(\lim _{\delta \rightarrow 1} \mathrm{E}_{t} \sum_{\tau=0}^{\infty}(1-\delta) \delta^{\tau} L_{t+\tau}=\mathrm{E}\left[L_{t}\right]\right)$. The unconditional mean of the period loss function satisfies

$$
\mathrm{E}\left[L_{t}\right]=\operatorname{Var}\left[p_{t}^{c}-p_{t-4}^{c}\right]+\lambda_{y} \operatorname{Var}\left[y_{t}-\bar{y}_{t}\right]+\lambda_{\Delta i} \operatorname{Var}\left[i_{t}-i_{t-1}\right]
$$

under the assumption that the unconditional mean of 4-quarter CPI inflation equals the inflation target $\left(\mathrm{E}\left[p_{t}^{c}-p_{t-4}^{c}\right]=\pi^{*}\right)$ and the unconditional mean of the output gap equals zero $\left(\mathrm{E}\left[y_{t}-\bar{y}_{t}\right]=0\right)$. Under these assumptions, optimal policy for different loss-function weights $\lambda_{y}$ and $\lambda_{\Delta i}$ results in efficient combinations of (unconditional) variances of inflation, the output gap, and the firstdifference of the nominal interest rate. These variances for different loss-function weights provide the efficient relevant policy trade-offs between stabilization of inflation and the output gap and interest-rate smoothing. Appendix $\mathrm{C}$ shows how the unconditional variances are computed. To investigate the role of alternative measures of the output gap in the loss function, we show the variance trade-offs for either the trend output gap or the unconditional output gap in the loss function. We first study the variance trade-offs when all shocks are active (figure 4.1), and then move on to an analysis of which type of shock influences the trade-offs most (figures 4.2 and 4.3). ${ }^{9}$ The curves referring to ZLB concern the case when the zero-lower-bound restriction on the nominal interest rate is imposed. They will be discussed in section 4.1.

In figure 4.1, the second row of the left column shows the variance of the trend output gap plotted against the variance of inflation, where inflation is 4-quarter CPI-inflation. The curve is obtained when varying the weight on output stabilization $\left(\lambda_{y}\right)$ in the loss function with the trend output gap, given a fixed weight on interest-rate smoothing $\left(\lambda_{\Delta i}=0.37\right)$. The third row of the left column shows the corresponding variance of the nominal interest rate plotted against the variance of inflation, and the fourth row of the same column shows the variance of the real exchange rate plotted against the variance of inflation. Each $\lambda_{y}$ results in a particular variance of inflation, and the figure should thus be read as if a vertical line through that level of inflation variance connects the three subplots. The curves are plotted for $\lambda_{y}$ between 0.0001 and 10. A circle denotes the combination of variances resulting from $\lambda_{y}=1$. On the solid curve only, the extreme low and high values for $\lambda_{y}$ are marked by a square and diamond, respectively. The right column shows the variances when the unconditional output gap is used in the loss function instead of the trend output gap.

\footnotetext{
${ }^{9}$ In order not to lengthen the paper we have in this section chosen to only look at the unconditional output gap and not the conditional output gap.
} 
Figure 4.1: Variance trade-offs when using either the trend or unconditional output gap in loss function and optimized simple instrument rule.
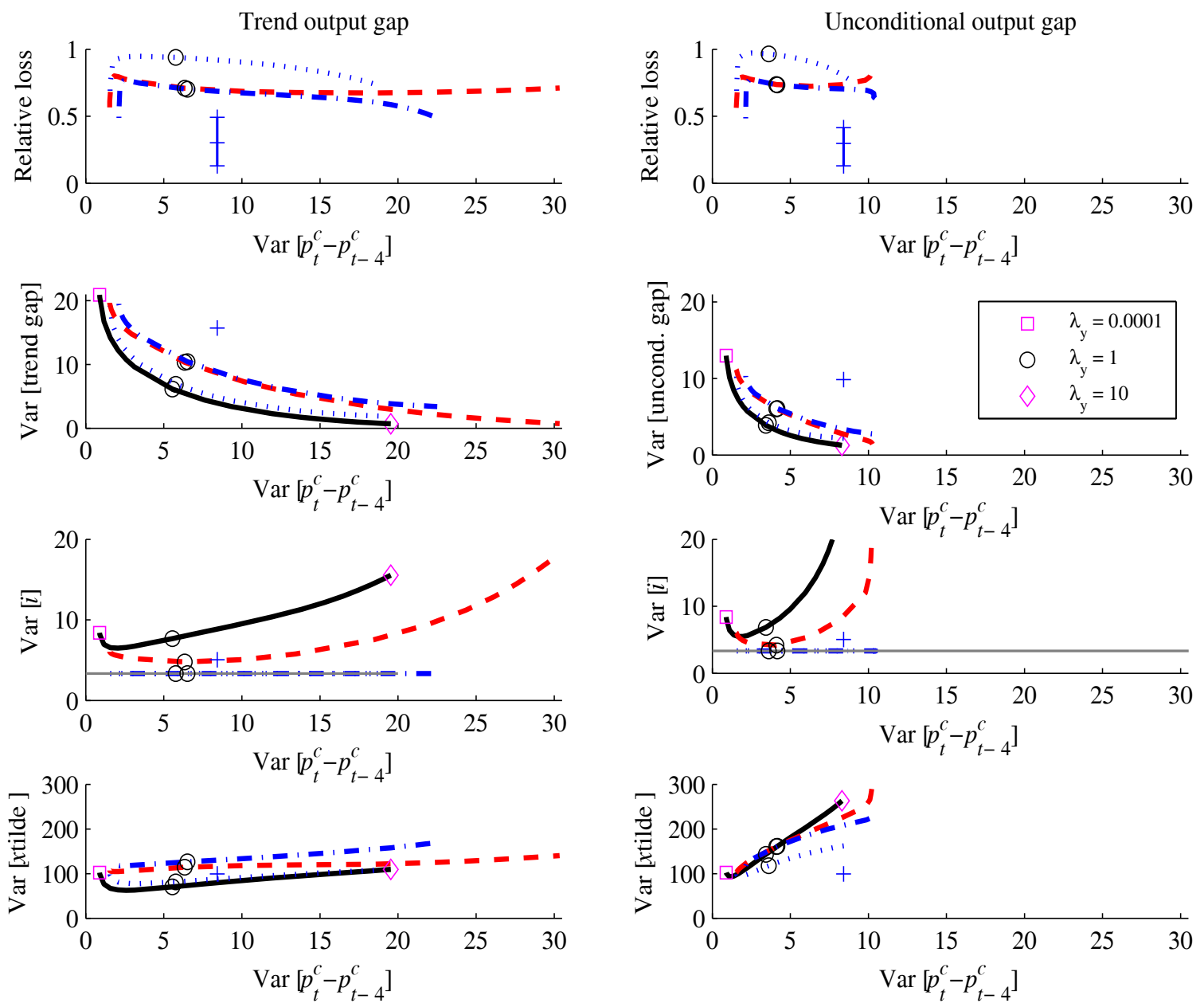

Optimal

In the figure, we compare the variance trade-offs under optimal policy (solid curve) with the variance obtained under the estimated instrument rule $(+)$ and an optimized simple instrument rule (dashed curve). The optimized simple instrument rule has the following form,

$$
i_{t}=\rho_{R} i_{t-1}+\left(1-\rho_{R}\right)\left[\rho_{\pi}\left(p_{t}^{c}-p_{t-1}^{c}-\pi^{*}\right)+\rho_{y}\left(y_{t}-\bar{y}_{t}\right)\right]
$$

where the response coefficients $\rho_{R}, \rho_{\pi}$, and $\rho_{y}$ are chosen to minimize the unconditional mean of the central bank loss function (4.1) for each given $\lambda_{y} \cdot{ }^{10}$ We use the same output gap (trend or unconditional) in the simple instrument rule (4.2) and the unconditional mean of the loss function

\footnotetext{
${ }^{10}$ We use Matlab's optimizers 'fminunc' and 'fminsearch' repeatedly to find the global optimum for the different response coefficients.
} 
(4.1). The resulting optimized response coefficients in the simple instrument rule (4.2) are reported in table 4.1. We include forward-looking variables dated in period $t$ in the simple instrument rule above, which means that the instrument rule not only depends on predetermined variables and is hence an implicit rather than explicit instrument rule. Consequently, since the interest rate then depends on forward-looking variables which in turn depend on the interest rate, the instrument rule is an equilibrium relation rather than an operational realistic instrument rule. We include forward-looking variables in the simple instrument rule as a way to allow the interest rate also in this case to respond to some current shocks and hence to be less at a disadvantage compared with the optimal policy.

Table 4.1: Optimized simple instrument rule

\begin{tabular}{c|cccccccccc}
\multicolumn{4}{c}{$i_{t}=\rho_{R} i_{t-1}+\rho_{\pi}\left(\pi_{t}-\pi^{*}\right)+\rho_{y}\left(y_{t}-\bar{y}_{t}\right)$} \\
\hline \hline & \multicolumn{4}{c}{ Trend output gap } & & \multicolumn{3}{c}{ Unconditional output gap } \\
$\lambda_{y}$ & $\rho_{R}$ & $\rho_{\pi}$ & $\rho_{y}$ & Loss & & $\rho_{R}$ & $\rho_{\pi}$ & $\rho_{y}$ & Loss \\
\hline 0.0001 & 1.03 & 0.51 & 0.003 & 1.97 & & 1.01 & 0.51 & -0.004 & 1.98 \\
0.01 & 1.03 & 0.51 & 0.004 & 2.16 & & 1.01 & 0.50 & -0.003 & 2.09 \\
0.11 & 1.02 & 0.47 & 0.01 & 4.07 & & 1.01 & 0.47 & 0.004 & 3.17 \\
0.21 & 1.01 & 0.44 & 0.02 & 5.88 & & 1.01 & 0.44 & 0.01 & 4.19 \\
0.31 & 1.01 & 0.42 & 0.02 & 7.59 & & 1.02 & 0.41 & 0.02 & 5.15 \\
0.41 & 1.01 & 0.39 & 0.02 & 9.21 & & 1.02 & 0.39 & 0.02 & 6.05 \\
0.51 & 1.02 & 0.36 & 0.03 & 10.73 & 1.02 & 0.37 & 0.03 & 6.90 \\
1 & 1.05 & 0.25 & 0.05 & 16.84 & & 1.03 & 0.32 & 0.06 & 10.38 \\
1.5 & 1.07 & 0.19 & 0.07 & 21.19 & & 1.00 & 0.32 & 0.13 & 12.90 \\
2 & 1.09 & 0.17 & 0.09 & 24.31 & & 0.96 & 0.32 & 0.21 & 14.60 \\
3 & 1.10 & 0.16 & 0.14 & 28.51 & & 0.90 & 0.25 & 0.33 & 16.91 \\
4 & 1.12 & 0.16 & 0.20 & 31.24 & & 0.90 & 0.24 & 0.40 & 18.74 \\
5 & 1.13 & 0.17 & 0.27 & 33.20 & & 0.91 & 0.25 & 0.45 & 20.46 \\
6 & 1.13 & 0.17 & 0.34 & 34.72 & & 0.92 & 0.26 & 0.49 & 22.10 \\
7 & 1.13 & 0.17 & 0.40 & 35.95 & 0.93 & 0.27 & 0.54 & 23.68 \\
8 & 1.13 & 0.17 & 0.47 & 36.98 & 0.93 & 0.29 & 0.58 & 25.20 \\
9 & 1.12 & 0.17 & 0.53 & 37.87 & 0.93 & 0.30 & 0.62 & 26.69 \\
10 & 1.12 & 0.17 & 0.59 & 38.66 & & 0.93 & 0.31 & 0.65 & 28.14 \\
\hline
\end{tabular}

Table 4.1 shows that the optimized coefficients of the instrument rule are such that the optimized simple instrument rules are generally "super-inertial," that is, $\rho_{R}$ is above unity. The exception is that $\rho_{R}$ is lower than unity for the unconditional output gap when $\lambda_{y}$ is sufficiently high (roughly above 1). Another property is that the response coefficients on the inflation (output gap) decreases (increases) as the weight on output-gap stabilization is increased. This property is not obvious and not general, since the mapping from loss function weights to optimal instrument-rule response coefficients is complicated and model-dependent. 
The top row in figure 4.1 shows the relative loss for the different polices, expressed as the ratio between the unconditional mean loss under the optimal policy and the unconditional mean loss under the non-optimal policies, plotted for each $\lambda_{y}$ against the inflation variance of the nonoptimal policy. Thus, the relative loss is bounded between zero and unity and shows what fraction of the loss for the non-optimal policy the loss for the optimal policy is. The dashed curve shows the relative loss under the optimized simple instrument rule. The vertical line marked with + shows the relative loss for the estimated instrument rule. The latter is plotted for different $\lambda_{y}$ against the constant inflation variance for the estimated instrument rule.

In the figure, we see that the central bank can improve on the estimated instrument rule by conducting optimal policy, since the loss under optimal policy is less than 0.5 of the loss under the estimated instrument rule. Optimizing the response coefficients of the simple instrument rule, however, closes a substantial part of the gap between the estimated instrument rule and the optimal policy, but the relative loss for the optimized simple instrument rule is still only about 0.75 , and inflation and output-gap variances are thus still inefficient and can be further reduced by optimal policy. Interestingly, the nominal interest rate variance is larger under optimal policy than under the estimated instrument rule, which contributes to the more favorable inflation output trade-off relative to the estimated instrument rule. Figure 4.1 also shows that the central bank appears to face a relatively sharp trade-off between stabilizing inflation and the output gap. If the central bank wants to decrease the variance of inflation from 20 to 1, then it has to accept an increase in the variance of output of about 20 , that is, the variance frontier has an "average" slope of about $-1 .{ }^{11}$ As can be seen from the right column of the second row in figure 4.1, the slope of the trade-off is about the same if the unconditional output gap is used in the loss function instead of the trend output gap. However, we see that the variance trade-off is more favorable and the variance curve is closer to origin for the unconditional output gap compared with that for the trend output gap. Thus, it is easier to stabilize the unconditional output gap than the trend output gap. Finally, the bottom row shows that lower output gap variance and higher inflation variance go with higher variance of the real exchange rate, so the real exchange rate is apparently implicitly adjusted to stabilize the output gap.

To examine which different shocks create the trade-offs in figure 4.1, figures 4.2 and 4.3 plot the variance trade-offs between inflation and the output gap for different subsets of active shocks, as well as the corresponding variances of the nominal interest rate and the real exchange rate plotted against

\footnotetext{
${ }^{11}$ We measure both inflation and the output gap in per cent, which implies that the variance is defined in terms of squared $\%$.
} 
each $\lambda_{y}$. We have divided the shocks into four different categories: domestic technology shocks (that is, stationary technology and investment specific technology shocks), markup shocks (that is, domestic, imported consumption, imported investment and export markup shocks), preference shocks (that is, consumption preference and labor supply shocks), and foreign shocks (that is, unit-root technology, asymmetric technology, risk premium and foreign VAR shocks, which are foreign inflation, output and interest rate shocks). It is important to notice that the parameters in the optimized simple instrument rule are optimized on the full set of shocks, not on each subset separately. Therefore, it is possible that the variance trade-offs between inflation and the output gap are not always downward sloping for a particular subset of shocks for the optimized simple instrument rule (but they are always downward sloping for the optimal policy, which responds optimally to each shock separately (see (2.7) and (2.8)).

Figure 4.2 refers to the case with the trend output gap in the loss function and the variance of the trend output gap. It shows that, in that case, the variance trade-offs between inflation and the trend output gap is predominantly driven by the domestic technology shocks. The reason is that the stationary technology shock affects actual output but not trend output. Even if the shock is efficient in the sense that it lowers inflation pressure and increases actual output, trend productivity is not affected and the output gap therefore increases and thus creates a trade-off between stabilizing inflation and the trend output gap. We also see from the figure that the central bank needs to balance inflation stabilization against output-gap stabilization for most of the different sets of shocks, as the variance frontiers are downward sloping for all subsets of shocks. This is partly due to the interest-rate smoothing term in the loss function and partly due to the open-economy aspects of the model. Since all variations in the interest rate also lead to fluctuations in the exchange rate, it matters for policy how, for example, the consumers substitute between domestic and imported goods. The third column of the figure shows that the variance of the real exchange rate is high for all the different categories of shocks (cost-push shocks as well as demand-oriented shocks). Finally, we see that the variances for the estimated instrument rule is rather close to the variance tradeoff for the optimal policy for all the categories of shocks except the foreign shocks, for which the estimated instrument rule is found to be very inefficient.

Figure 4.3 refers to the case with the unconditional output gap in the loss function and the variance of the unconditional output gap. In this case, the variance trade-off is mainly caused by preference shocks rather than domestic technology shocks. Since productivity shocks influence both unconditional potential output and actual output, the unconditional output gap will be less affected 
by this type of shock compared with the trend output gap. This means that the central bank does not have to trade off inflation stability for output-gap stability to the same extent when using the unconditional output gap in the loss function. It should also be noted that the unconditional output gap is negatively affected whereas the trend output gap is positively affected by an increase in productivity (see figure 3.1), which implies that a lower interest rate stabilizes inflation and the flexprice output gap simultaneously. The labor supply shock and the consumption preference shock, on the other hand, affect inflation and the output gap with opposite signs irrespective of which output gap definition is used in the loss function. In figure 3.3 we saw that the central bank cannot simultaneously stabilize both the increase in inflation and the negative (unconditional, conditional, and trend) output gap in response to labor supply (wage markup) shocks. So this shock, along with the price markup shocks are the main sources of the trade-off between inflation and the unconditional output gap.

\subsection{The zero lower bound on nominal interest rates}

As is evident in figure 4.1, the interest-rate variance is relatively high under both the optimized instrument rule and the optimal policy. This means that the zero lower bound (ZLB) for the nominal interest rate may occasionally bind when shocks hit the economy. An approximation to the (non-linear) constraint that the nominal interest rate must be non-negative is to limit the variance of the nominal interest rate and thereby reduce the probability that the interest rate violates the ZLB. This approximation allows us to keep the linear-quadratic approach and focus on the second moments, but a potential drawback is of course that the approximation also limits upward movements in the nominal interest rate. We nevertheless adopt this approximation (see Woodford [20] for a discussion). ${ }^{12}$

When optimizing the response coefficients of the simple instrument rule we therefore add the restriction there is only a $1 \%$ probability of hitting the ZLB. With an assumed steady state value for the nominal interest rate of $4.25 \%$ this implies that the variance of of the nominal interest rate is not allowed to be larger than 3.34\%. The dashed-dotted curves in figure 4.1 show the outcome of this procedure. Limiting the variance in the nominal interest rate implies the central bank can not stabilize output and inflation to the same extent, and the variance frontier moves slightly further out compared with when the ZLB is not imposed. For small $\lambda_{y}$ the difference is not particularly

\footnotetext{
${ }^{12}$ In a smaller model it would be possible to deal with the consequences of the zero lower bound in a more rigorous fashion, for example along the lines of Adam and Billi [1].
} 
Figure 4.2: Variance trade-offs between when different shocks are active. Trend output gap in the loss function.
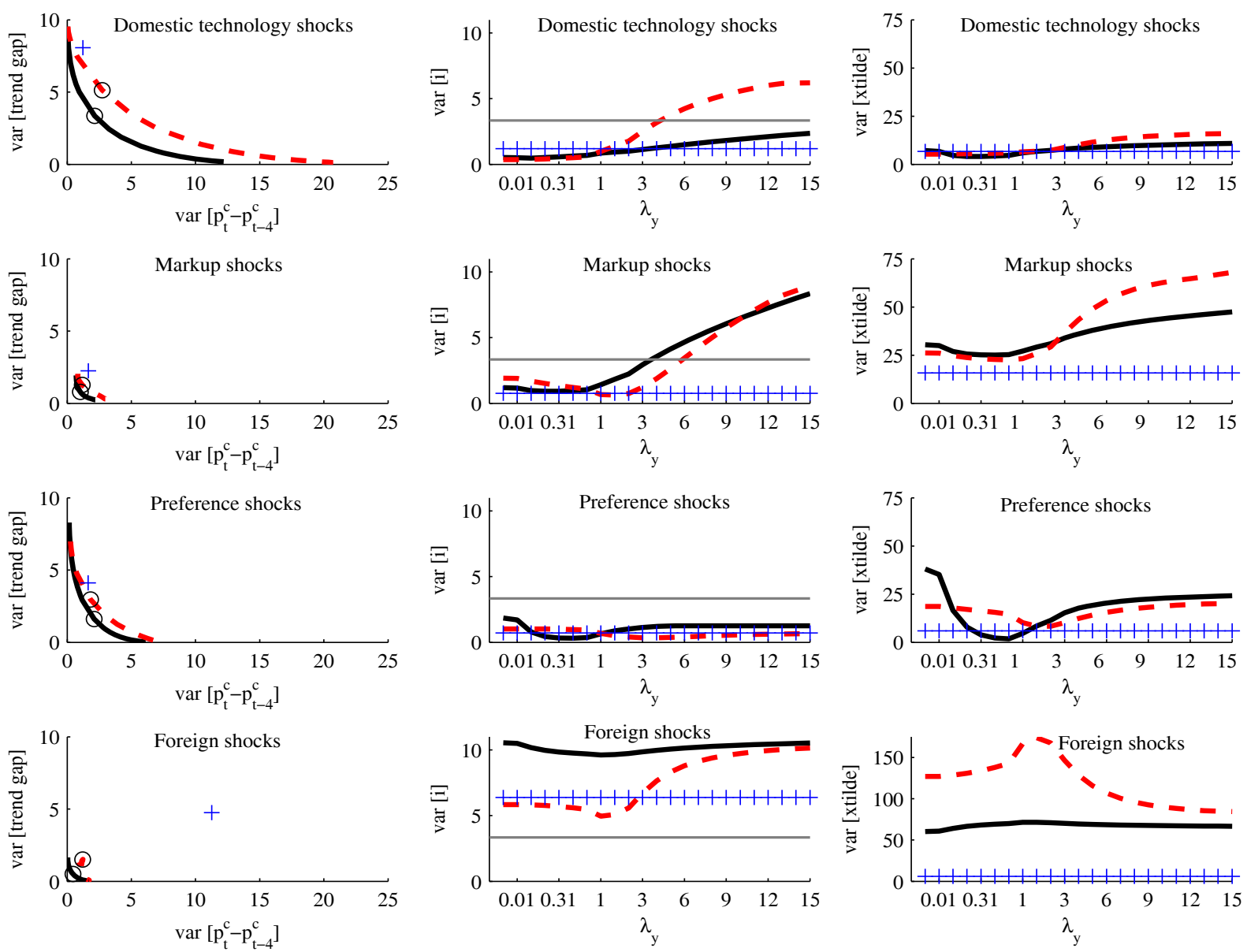

Optimal $=-$ Optimized instrument rule

$+\quad$ Estimated rule

pronounced, but for large $\lambda_{y}$ the ZLB restriction results in a much larger output-gap variance that is not compensated by the decrease in inflation variance and hence the loss increases substantially. A larger output variability also feeds into a somewhat higher variance of the real exchange rate when the trend output gap is considered. It should, however, also be noted that the restriction on the variance of the nominal interest rate is strongly binding. For large weights on output-gap stabilization, the interest rate variance is almost six (nine) times as high when the ZLB is not imposed in the trend (unconditional) output-gap case. From this perspective, the impact on the inflation-output variance trade-off seems rather modest.

We also impose the zero lower bound on the nominal interest rate on the optimal policy, in 
Figure 4.3: Variance trade-offs when different subsets of shocks are active. Unconditional output gap in loss function.
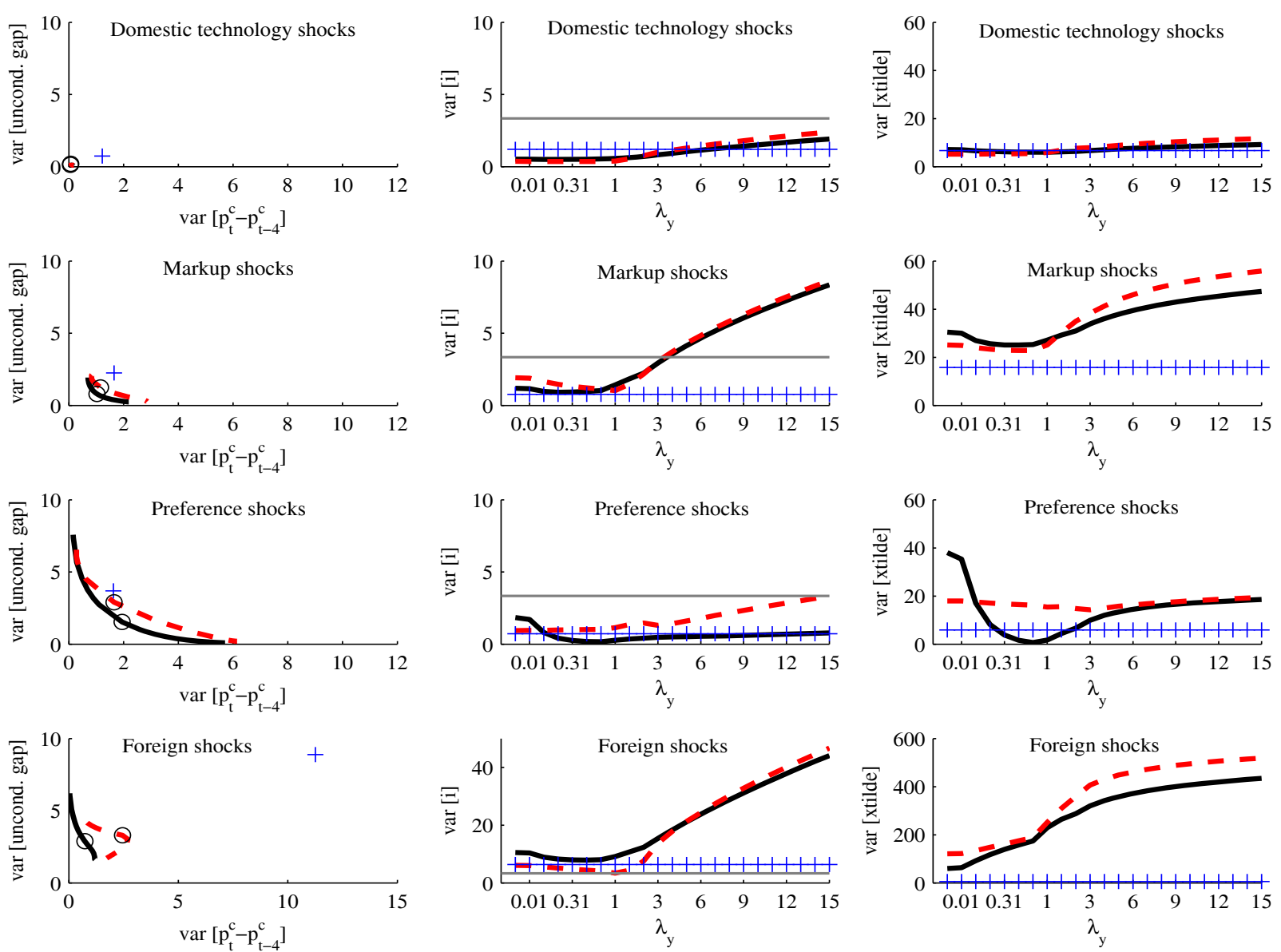

Optimal -- Optimized instrument rule $\quad+$ Estimated rule

this case by adding an extra interest-rate variance argument, $\lambda_{i} i_{t}{ }^{2}$, to the loss function in (2.5) and gradually increasing $\lambda_{i}$ until the variance of the nominal interest rate is not larger than $3.34 \%$. The resulting variance trade-offs are depicted as dotted curves in figure 4.1. We see that the trade-off between inflation and output-gap variance shifts out a bit but not much. So even if the interest-rate variance in the unrestricted case is larger with optimal policy than with the optimized simple instrument rule, the zero lower bond appears to have about the same impact on the trade-off between inflation and output-gap variance. ${ }^{13}$

\footnotetext{
${ }^{13}$ The interest-rate variance can also be reduced by increasing the weight on interest-rate smoothing, $\lambda_{\Delta i}$. However, this deteriorates the trade-off between inflation and output-gap variance quite a bit (not shown) and is hence an inefficient way of reducing the inteterest-rate variance compared to increasing the weight on interest-rate variance, $\lambda_{i}$.
} 


\section{Conclusions}

This paper has examined how the transmission of shocks depends on the conduct of monetary policy. We have illustrated that policy with an estimated instrument rule or optimal policy can generate quite different impulse responses to some shocks, even if the response coefficients and loss-function parameters have been estimated from the same macroeconomic time series.

We have also shown that it matters which output-gap definition the central bank uses in its loss function. Depending on whether it is the trend output gap (between output and trend output) or the unconditional output gap (between output and unconditional flexprice potential output, the hypothetical output level that would prevail if prices and wages were entirely flexible and had been so forever) that is included in the loss function, the central bank faces different trade-offs between stabilizing inflation and the output gap. According to our analysis, the trade-off between stabilizing inflation and the output gap is more favorable for the unconditional output gap than for the commonly used trend output gap. However, abandoning the trend output gap in favor of the unconditional or conditional output gap would also be associated with an increase in the variance of output. However, abandoning the trend output gap in favor of the unconditional or conditional output gap would also be associated with an increase in the variance of output since conditional/unconditional potential output fluctuates more than trend output due to the fact that stationary but persistent technology shocks are important to explain business cycle fluctuations in the Swedish economy. On the other hand, because the trade-off between output-gap stabilization and inflation stabilization is more favorable for unconditional and conditional output gaps than for trend output gaps, abandoning the trend output gap for one of the other output gaps may be associated with lower inflation variability.

The sensitivity of the results when imposing the zero lower bound for the nominal interest rate was also examined. While our approach to address the effects of imposing the zero lower bound is an approximation, the results suggest that this assumption has about the same implications for the optimized simple instrument rule and the optimal policy. 


\section{Appendix}

\section{A. The Ramses model}

The model economy includes four different categories of operating firms. These are domestic goods firms, importing consumption, importing investment, and exporting firms, respectively. Within each category there is a continuum of firms that each produces a differentiated good. The domestic goods firms produce their goods using capital and labor inputs, and sell them to a retailer which transforms the intermediate products into a homogenous final good that in turn is sold to the households.

The final domestic good is a composite of a continuum of $i$ differentiated goods, each supplied by a different firm, which follows the constant elasticity of substitution (CES) function

$$
Y_{t}=\left[\int_{0}^{1}\left(Y_{i t}\right)^{\frac{1}{\lambda_{t}^{d}}} d i\right]^{\lambda_{t}^{d}}, 1 \leq \lambda_{t}^{d}<\infty
$$

where $\lambda_{t}^{d}$ is a stochastic process that determines the time-varying flexible-price markup in the domestic goods market. The demand for firm $i$ 's differentiated product, $Y_{i t}$, follows

$$
Y_{i t}=\left(\frac{P_{i t}^{d}}{P_{t}^{d}}\right)^{-\frac{\lambda_{t}^{d}}{\lambda_{t}^{d}-1}} Y_{t}
$$

where $P_{t}^{d}$ is the output price of the final good firm and $P_{i t}^{d}$ is its input price. The domestic production is exposed to unit root technology growth. The production function for intermediate good $i$ is given by

$$
Y_{i t}=z_{t}^{1-\alpha} \epsilon_{t} K_{i t}^{\alpha} H_{i t}^{1-\alpha}-z_{t} \phi
$$

where $z_{t}$ is a unit-root technology shock capturing world productivity, $\epsilon_{t}$ is a domestic covariance stationary technology shock, $K_{i t}$ the capital stock and $H_{i t}$ denotes homogeneous labor hired by the $i^{t h}$ firm. A fixed cost $z_{t} \phi$ is included in the production function. We set this parameter so that profits are zero in steady state.

We allow for working capital by assuming that a fraction $\nu$ of the intermediate firms' wage bill has to be financed in advance through loans from a financial intermediary. Cost minimization yields the following nominal marginal cost for intermediate firm $i$ :

$$
M C_{t}^{d}=\frac{1}{(1-\alpha)^{1-\alpha}} \frac{1}{\alpha^{\alpha}}\left(R_{t}^{k}\right)^{\alpha}\left[W_{t}\left(1+\nu\left(R_{t-1}-1\right)\right)\right]^{1-\alpha} \frac{1}{\left(z_{t}\right)^{1-\alpha}} \frac{1}{\epsilon_{t}},
$$


where $R_{t}^{k}$ is the gross nominal rental rate per unit of capital, $R_{t-1}$ the gross nominal (economy wide) interest rate, and $W_{t}$ the nominal wage rate per unit of aggregate, homogeneous, labor $H_{i t}$.

Each of the domestic goods firms is subject to price stickiness through an indexation variant of the Calvo [8] model. Since we have a time-varying inflation target in the model we allow for partial indexation to the current inflation target, but also to last period's inflation rate in order to allow for a lagged pricing term in the Phillips curve. Each intermediate firm faces in any period a probability $\left(1-\xi_{d}\right)$ that it can reoptimize its price. The reoptimized price is denoted $P_{t}^{d, n e w}{ }^{14}$ The different firms maximize profits taking into account that there might not be a chance to optimally change the price in the future. Firm $i$ therefore faces the following optimization problem when setting its price

$$
\begin{gathered}
\max _{P_{t}^{d, \text { new }}} \mathrm{E}_{t} \sum_{s=0}^{\infty}\left(\beta \xi_{d}\right)^{s} v_{t+s}\left[\left(\left(\pi_{t}^{d} \pi_{t+1}^{d} \ldots \pi_{t+s-1}^{d}\right)^{\kappa_{d}}\left(\bar{\pi}_{t+1}^{c} \bar{\pi}_{t+2}^{c} \ldots \bar{\pi}_{t+s}^{c}\right)^{1-\kappa_{d}} P_{t}^{d, \text { new }}\right) Y_{i, t+s}\right. \\
\left.-M C_{i, t+s}^{d}\left(Y_{i, t+s}+z_{t+s} \phi^{j}\right)\right]
\end{gathered}
$$

where the firm is using the stochastic household discount factor $\left(\beta \xi_{d}\right)^{s} v_{t+s}$ to make profits conditional upon utility. $\beta$ is the discount factor, and $v_{t+s}$ the marginal utility of the households' nominal income in period $t+s$, which is exogenous to the intermediate firms. $\pi_{t}^{d}$ denotes inflation in the domestic sector, $\bar{\pi}_{t}^{c}$ a (perceived) time-varying inflation target and $M C_{i t}^{d}$ the nominal marginal cost.

The first order condition of the profit maximization problem in equation (A.5) yields the following log-linearized Phillips curve:

$$
\begin{aligned}
\left(\widehat{\pi}_{t}^{d}-\widehat{\bar{\pi}}_{t}^{c}\right)= & \frac{\beta}{1+\kappa_{d} \beta}\left(\mathrm{E}_{t} \widehat{\pi}_{t+1}^{d}-\rho_{\pi} \widehat{\bar{\pi}}_{t}^{c}\right)+\frac{\kappa_{d}}{1+\kappa_{d} \beta}\left(\widehat{\pi}_{t-1}^{d}-\widehat{\bar{\pi}}_{t}^{c}\right) \\
& -\frac{\kappa_{d} \beta\left(1-\rho_{\pi}\right)}{1+\kappa_{d} \beta} \widehat{\bar{\pi}}_{t}^{c}+\frac{\left(1-\xi_{d}\right)\left(1-\beta \xi_{d}\right)}{\xi_{d}\left(1+\kappa_{d} \beta\right)}\left(\widehat{m c}_{t}^{d}+\widehat{\lambda}_{t}^{d}\right),
\end{aligned}
$$

where a hat denotes log-deviation from steady state (that is, $\hat{X}_{t}=\ln X_{t}-\ln X$ ).

We now turn to the import and export sectors. There is a continuum of importing consumption and investment firms that each buys a homogenous good at price $P_{t}^{*}$ in the world market, and converts it into a differentiated good through a brand naming technology. The exporting firms buy the (homogenous) domestic final good at price $P_{t}^{d}$ and turn this into a differentiated export good through the same type of brand naming. The nominal marginal cost of the importing and exporting firms are thus $S_{t} P_{t}^{*}$ and $P_{t}^{d} / S_{t}$, respectively, where $S_{t}$ is the nominal exchange rate (domestic currency per unit of foreign currency). The differentiated import and export goods

\footnotetext{
14 For the firms that are not allowed to reoptimize their price, we adopt the indexation scheme $P_{t+1}^{d}=$ $\left(\pi_{t}^{d}\right)^{\kappa_{d}}\left(\bar{\pi}_{t+1}^{c}\right)^{1-\kappa_{d}} P_{t}^{d}$ where $\kappa_{d}$ is an indexation parameter.
} 
are subsequently aggregated by an import consumption, import investment and export packer, respectively, so that the final import consumption, import investment, and export good is each a CES composite according to the following:

$$
C_{t}^{m}=\left[\int_{0}^{1}\left(C_{i t}^{m}\right)^{\frac{1}{\lambda_{t}^{m c}}} d i\right]^{\lambda_{t}^{m c}}, \quad I_{t}^{m}=\left[\int_{0}^{1}\left(I_{i t}^{m}\right)^{\frac{1}{\lambda_{t}^{m i}}} d i\right]^{\lambda_{t}^{m i}}, \quad X_{t}=\left[\int_{0}^{1}\left(X_{i t}\right)^{\frac{1}{\lambda_{t}^{x}}} d i\right]^{\lambda_{t}^{x}},
$$

where $1 \leq \lambda_{t}^{j}<\infty$ for $j=\{m c, m i, x\}$ is the time-varying flexible-price markup in the import consumption $(m c)$, import investment $(m i)$ and export $(x)$ sector. By assumption the continuum of consumption and investment importers invoice in the domestic currency and exporters in the foreign currency. In order to allow for short-run incomplete exchange rate pass-through to import as well as export prices we therefore introduce nominal rigidities in the local currency price. ${ }^{15}$ This is modeled through the same type of Calvo setup as above. The price setting problems of the importing and exporting firms are completely analogous to that of the domestic firms in equation (A.5), and the demand for the differentiated import and export goods follow similar expressions as to equation (A.2). In total there are thus four specific Phillips curve relations determining inflation in the domestic, import consumption, import investment and export sectors.

In the model economy there is also a continuum of households which attain utility from consumption, leisure and real cash balances. The preferences of household $j$ are given by

$$
\mathrm{E}_{0}^{j} \sum_{t=0}^{\infty} \beta^{t}\left[\zeta_{t}^{c} \ln \left(C_{j t}-b C_{j, t-1}\right)-\zeta_{t}^{h} A_{L} \frac{\left(h_{j t}\right)^{1+\sigma_{L}}}{1+\sigma_{L}}+A_{q} \frac{\left(\frac{Q_{j t}}{z_{t} P_{t}^{d}}\right)^{1-\sigma_{q}}}{1-\sigma_{q}}\right],
$$

where $C_{j t}, h_{j t}$ and $Q_{j t} / P_{t}^{d}$ denote the $j^{t h}$ household's levels of aggregate consumption, labor supply and real cash holdings, respectively. Consumption is subject to habit formation through $b C_{j, t-1}$, such that the household's marginal utility of consumption is increasing in the quantity of goods consumed last period. $\zeta_{t}^{c}$ and $\zeta_{t}^{h}$ are persistent preference shocks to consumption and labor supply, respectively. To make cash balances in equation (A.8) stationary when the economy is growing they are scaled by the unit root technology shock $z_{t}$. Households consume a basket of domestically produced goods and imported products which are supplied by the domestic and importing consumption firms, respectively. Aggregate consumption is assumed to be given by the following constant elasticity of substitution (CES) function:

$$
C_{t}=\left[\left(1-\omega_{c}\right)^{1 / \eta_{c}}\left(C_{t}^{d}\right)^{\left(\eta_{c}-1\right) / \eta_{c}}+\omega_{c}^{1 / \eta_{c}}\left(C_{t}^{m}\right)^{\left(\eta_{c}-1\right) / \eta_{c}}\right]^{\eta_{c} /\left(\eta_{c}-1\right)},
$$

\footnotetext{
15 There would be complete pass-through in the absence of nominal rigidities, since there are neither distribution costs in the import and export sectors nor an endogenous pricing to market behavior among the firms in the model.
} 
where $C_{t}^{d}$ and $C_{t}^{m}$ are consumption of the domestic and imported good, respectively. $\omega_{c}$ is the share of imports in consumption, and $\eta_{c}$ is the elasticity of substitution across consumption goods.

The households invest in a basket of domestic and imported investment goods to form the capital stock, and decide how much capital to rent to the domestic firms given costs of adjusting the investment rate. The households can increase their capital stock by investing in additional physical capital $\left(I_{t}\right)$, taking one period to come in action. The capital accumulation equation is given by

$$
K_{t+1}=(1-\delta) K_{t}+\Upsilon_{t}\left(1-\tilde{S}\left(I_{t} / I_{t-1}\right)\right) I_{t},
$$

where $\tilde{S}\left(I_{t} / I_{t-1}\right)$ determines the investment adjustment costs through the estimated parameter $\tilde{S}^{\prime \prime}$, and $\Upsilon_{t}$ is a stationary investment-specific technology shock. Total investment is assumed to be given by a CES aggregate of domestic and imported investment goods ( $I_{t}^{d}$ and $I_{t}^{m}$, respectively) according to

$$
I_{t}=\left[\left(1-\omega_{i}\right)^{1 / \eta_{i}}\left(I_{t}^{d}\right)^{\left(\eta_{i}-1\right) / \eta_{i}}+\omega_{i}^{1 / \eta_{i}}\left(I_{t}^{m}\right)^{\left(\eta_{i}-1\right) / \eta_{i}}\right]^{\eta_{i} /\left(\eta_{i}-1\right)},
$$

where $\omega_{i}$ is the share of imports in investment, and $\eta_{i}$ is the elasticity of substitution across investment goods.

Further, each household is a monopoly supplier of a differentiated labor service which implies that they can set their own wage. After having set their wage, households supply the firms' demand for labor at the going wage rate. Each household sells its labor to a firm which transforms household labor into a homogenous good that is demanded by each of the domestic goods producing firms. Wage stickiness is introduced through the Calvo [8] setup, with partial indexation to last period's CPI inflation rate, the current inflation target and the technology growth. Household $j$ reoptimizes its nominal wage rate $W_{j t}^{\text {new }}$ according to the following

$$
\begin{gathered}
\max _{W_{j t}^{\text {new }}} \mathrm{E}_{t} \sum_{s=0}^{\infty}\left(\beta \xi_{w}\right)^{s}\left[-\zeta_{t+s}^{h} A_{L} \frac{\left(h_{j, t+s}\right)^{1+\sigma_{L}}}{1+\sigma_{L}}+\right. \\
\left.v_{t+s} \frac{\left(1-\tau_{t+s}^{y}\right)}{\left(1+\tau_{t+s}^{w}\right)}\left(\left(\pi_{t}^{c} \ldots \pi_{t+s-1}^{c}\right)^{\kappa_{w}}\left(\bar{\pi}_{t+1}^{c} \ldots \bar{\pi}_{t+s}^{c}\right)^{\left(1-\kappa_{w}\right)}\left(\mu_{z, t+1} \ldots \mu_{z, t+s}\right) W_{j t}^{n e w}\right) h_{j, t+s}\right],
\end{gathered}
$$

where $\xi_{w}$ is the probability that a household is not allowed to reoptimize its wage, $\tau_{t}^{y}$ a labor income tax, $\tau_{t}^{w}$ a pay-roll tax (paid for simplicity by the households), and $\mu_{z t}=z_{t} / z_{t-1}$ is the growth rate of the permanent technology level. ${ }^{16}$

The households can accumulate capital, save in domestic and foreign bonds, and also hold cash. The choice between domestic and foreign bond holdings balances into an arbitrage condition pinning

\footnotetext{
16 For the households that are not allowed to reoptimize, the indexation scheme is $W_{j, t+1}=$ $\left(\pi_{t}^{c}\right)^{\kappa_{w}}\left(\bar{\pi}_{t+1}^{c}\right)^{\left(1-\kappa_{w}\right)} \mu_{z, t+1} W_{j, t}^{n e w}$, where $\kappa_{w}$ is an indexation parameter.
} 
down expected exchange rate changes (that is, an uncovered interest parity condition). To ensure a well-defined steady-state in the model, we assume that there is a premium on the foreign bond holdings which depends on the aggregate net foreign asset position of the domestic households, following, for instance Schmitt-Grohé and Uribe [17]. A common problem with open-economy DSGE models is that they typically do not provide enough persistence to generate a hump-shaped response of the real exchange rate after a shock to monetary policy, which is commonly found in estimated VARs. A novel feature with our specification of the risk premium is the inclusion of the expected change in the exchange rate $\mathrm{E}_{t} S_{t+1} / S_{t-1}$. This is based on the observation that risk premia are strongly negatively correlated with the expected change in the exchange rate (that is, the expected depreciation), see for instance Duarte and Stockman [11]. This pattern is often referred to as the "forward premium puzzle". The risk premium is given by:

$$
\Phi\left(a_{t}, S_{t}, \tilde{\phi}_{t}\right)=\exp \left(-\tilde{\phi}_{a}\left(a_{t}-\bar{a}\right)-\tilde{\phi}_{s}\left(\frac{\mathrm{E}_{t} S_{t+1}}{S_{t}} \frac{S_{t}}{S_{t-1}}-1\right)+\tilde{\phi}_{t}\right),
$$

where $a_{t} \equiv\left(S_{t} B_{t}^{*}\right) /\left(P_{t} z_{t}\right)$ is the net foreign asset position, and $\tilde{\phi}_{t}$ is a shock to the risk premium. Consistent with the empirical evidence the idea here is that the domestic investors will require a lower expected return on their foreign bond holdings relative to their domestic deposits if the future exchange rate is easier to predict (that is, if the exchange rate is expected to depreciate consecutively). However, this formulation is not structural in the sense that such a risk premium can be associated with the utility function in (A.8). The UIP condition in its log-linearized form is given by:

$$
\widehat{R}_{t}-\widehat{R}_{t}^{*}=\left(1-\widetilde{\phi}_{s}\right) \mathrm{E}_{t} \Delta \widehat{S}_{t+1}-\widetilde{\phi}_{s} \Delta \widehat{S}_{t}-\widetilde{\phi}_{a} \widehat{a}_{t}+\widehat{\widetilde{\phi}}_{t}
$$

where $\Delta$ is the first difference operator, and $\widehat{R}_{t}$ denotes the domestic nominal interest rate, and $\widehat{R}_{t}^{*}$ the foreign nominal interest rate. By setting $\tilde{\phi}_{s}=0$ we obtain the UIP condition typically used in small open-economy models. In the empirical analysis we formally test which specification is supported by the data.

Since Sweden went from a "fixed" to a floating exchange rate/inflation targeting regime in December 1992, we want to allow for a discrete break in the parameters in the instrument rule (2.9) to account for a policy regime shift. It is not obvious, however, how one should model policy prior to 1993Q1. We assume that

$$
\theta_{R t}=\left\{\begin{array}{ll}
\theta_{R 1}, & \text { if } t<1993 \mathrm{Q} 1 \\
\theta_{R 2}, & \text { if } t \geq 1993 \mathrm{Q} 1
\end{array},\right.
$$

where $\theta_{R 1}$ captures the behavior of the central bank pre inflation targeting and $\theta_{R 2}$ captures the behavior during the inflation targeting regime. ALLV [5] provides further discussion of why a 
Taylor-type instrument rule may provide a good approximation of the conduct of monetary policy also before the adoption of an inflation target, when Sweden had a fixed exchange rate.

The structural shock processes in the model is given in log-linearized form by the univariate representation

$$
\hat{\varsigma}_{t}=\rho_{\varsigma} \hat{\varsigma}_{t-1}+\varepsilon_{\varsigma t}, \quad \varepsilon_{\varsigma t} \stackrel{i i d}{\sim} N\left(0, \sigma_{\varsigma}^{2}\right)
$$

where $\varsigma_{t}=\left\{\mu_{z t}, \epsilon_{t}, \lambda_{t}^{j}, \zeta_{t}^{c}, \zeta_{t}^{h}, \Upsilon_{t}, \tilde{\phi}_{t}, \varepsilon_{R t}, \bar{\pi}_{t}^{c}, \tilde{z}_{t}^{*}\right\}$ and $j=\{d, m c, m i, x\}$

The government spends resources on consuming part of the domestic good, and collects taxes from the households. The resulting fiscal surplus/deficit plus the seigniorage are assumed to be transferred back to the households in a lump sum fashion. Consequently, there is no government debt. The fiscal policy variables - taxes on capital income, labor income, consumption, and the payroll, together with (HP-detrended) government expenditures - are assumed to follow an identified VAR model with two lags.

To simplify the analysis we adopt the assumption that the foreign prices, output (HP-detrended) and interest rate are exogenously given by an identified VAR model with four lags. Both the foreign and the fiscal VAR models are being estimated, using uninformative priors, ahead of estimating the structural parameters in the DSGE model. ${ }^{17}$

To clear the final goods market, the foreign bond market, and the loan market for working capital, the following three constraints must hold in equilibrium:

$$
\begin{gathered}
C_{t}^{d}+I_{t}^{d}+G_{t}+C_{t}^{x}+I_{t}^{x} \leq z_{t}^{1-\alpha} \epsilon_{t} K_{t}^{\alpha} H_{t}^{1-\alpha}-z_{t} \phi \\
S_{t} B_{t+1}^{*}=S_{t} P_{t}^{x}\left(C_{t}^{x}+I_{t}^{x}\right)-S_{t} P_{t}^{*}\left(C_{t}^{m}+I_{t}^{m}\right)+R_{t-1}^{*} \Phi\left(a_{t-1}, \widetilde{\phi}_{t-1}\right) S_{t} B_{t}^{*}, \\
\nu W_{t} H_{t}=\mu_{t} M_{t}-Q_{t},
\end{gathered}
$$

where $G_{t}$ is government expenditures, $C_{t}^{x}$ and $I_{t}^{x}$ are the foreign demand for export goods which follow CES aggregates with elasticity $\eta_{f}$, and $\mu_{t}=M_{t+1} / M_{t}$ is the monetary injection by the central bank. When defining the demand for export goods, we introduce a stationary asymmetric (or foreign) technology shock $\tilde{z}_{t}^{*}=z_{t}^{*} / z_{t}$, where $z_{t}^{*}$ is the permanent technology level abroad, to allow for temporary differences in permanent technological progress domestically and abroad.

\footnotetext{
${ }^{17}$ The reason why we include foreign output HP-detrended and not in growth rates in the VAR is that the level of foreign output enters the DSGE model (e.g., in the aggregate resource constraint). In the state-space representation of the model, which links the theoretical model to the observed data, we subsequently add the unit-root world productivity shock and the stationary asymmetric (or foreign) technology shock to the business cycle component of foreign output in order to obtain the observed level of foreign GDP. This enables us to identify the stationary asymmetric technology shock, since the process for detrended foreign output is identified from the VAR and the process for the (unit root) world productivity is identified from this and the domestic quantities.
} 


\section{B. Parameters}

In table B.1 we report the parameters we have chosen to calibrate. These parameters are mostly related to the steady-state values of the observed variables (that is, the great ratios: $C / Y, I / Y$ and $G / Y)$. Table A.2 shows the prior and posterior distributions obtained in ALLS [2].

Table B.1: Calibrated parameters

\begin{tabular}{|c|c|c|}
\hline Parameter & Description & Calibrated value \\
\hline$\beta$ & Households' discount factor & 0.999999 \\
\hline$\alpha$ & Capital share in production & 0.25 \\
\hline$\eta_{c}$ & Substitution elasticity between $C_{t}^{d}$ and $C_{t}^{m}$ & 5 \\
\hline$\sigma_{a}$ & Capital utilization cost parameter & $1,000,000$ \\
\hline$\mu$ & Money growth rate (quarterly rate) & 1.010445 \\
\hline$\mu_{z}$ & Technology growth rate (quarterly rate) & 1.005455 \\
\hline$\sigma_{L}$ & Labor supply elasticity & 1 \\
\hline$\delta$ & Depreciation rate & 0.025 \\
\hline$\lambda_{w}$ & Wage markup & 1.30 \\
\hline$\omega_{i}$ & Share of imported investment goods & 0.50 \\
\hline$\omega_{c}$ & Share of imported consumption goods & 0.35 \\
\hline$\nu$ & Share of wage bill financed by loans & 1 \\
\hline$\tau^{y}$ & Labor income tax rate & 0.30 \\
\hline$\tau^{c}$ & Consumption tax rate & 0.24 \\
\hline$\tau^{k}$ & Capital income tax rate & 0.00 \\
\hline$\rho_{\bar{\pi}}$ & Inflation target persistence & 0.975 \\
\hline$g_{r}$ & Government expenditures-output ratio & 0.30 \\
\hline
\end{tabular}


Table B.2: Prior and posterior distributions

\begin{tabular}{|c|c|c|c|c|c|c|c|c|c|c|}
\hline \multirow[t]{2}{*}{ Parameter } & & \multicolumn{3}{|c|}{ Prior distribution } & \multicolumn{6}{|c|}{ Posterior distribution } \\
\hline & & type & mean & $\begin{array}{l}\text { std.d. } \\
/ \text { df }\end{array}$ & \multicolumn{2}{|c|}{\begin{tabular}{cc}
\multicolumn{2}{c}{ Policy rule } \\
mode & std.d. \\
& Hess.
\end{tabular}} & \multicolumn{2}{|c|}{$\begin{array}{l}\text { Loss function } \\
\text { mode } \quad \text { std.d. } \\
\end{array}$} & \multicolumn{2}{|c|}{$\begin{array}{l}\text { Loss params. } \\
\text { mode } \\
\text { std.d. } \\
\text { Hess. }\end{array}$} \\
\hline Calvo wages & $\xi_{w}$ & beta & 0.750 & 0.050 & 0.719 & 0.045 & 0.719 & 0.042 & & \\
\hline Calvo domestic prices & $\xi_{d}^{\infty}$ & beta & 0.750 & 0.050 & 0.712 & 0.039 & 0.737 & 0.043 & & \\
\hline Calvo import cons. prices & $\xi_{m, c}$ & beta & 0.750 & 0.050 & 0.868 & 0.018 & 0.859 & 0.016 & & \\
\hline Calvo import inv. prices & $\xi_{m, i}$ & beta & 0.750 & 0.050 & 0.933 & 0.010 & 0.929 & 0.011 & & \\
\hline Calvo export prices & $\xi_{x}$ & beta & 0.750 & 0.050 & 0.898 & 0.019 & 0.889 & 0.025 & & \\
\hline Indexation wages & $\kappa_{w}$ & beta & 0.500 & 0.150 & 0.445 & 0.124 & 0.422 & 0.115 & & \\
\hline Indexation prices & $\kappa_{d}$ & beta & 0.500 & 0.150 & 0.180 & 0.051 & 0.173 & 0.050 & & \\
\hline Markup domestic & $\lambda_{f}$ & truncnormal & 1.200 & 0.050 & 1.192 & 0.049 & 1.176 & 0.050 & & \\
\hline Markup imported cons. & $\lambda_{m, c}$ & truncnormal & 1.200 & 0.050 & 1.020 & 0.028 & 1.021 & 0.029 & & \\
\hline Markup.imported invest. & $\lambda_{m, i}$ & truncnormal & 1.200 & 0.050 & 1.137 & 0.051 & 1.154 & 0.049 & & \\
\hline Investment adj. cost & $\tilde{S}^{\prime \prime}$ & normal & 7.694 & 1.500 & 7.951 & 1.295 & 7.684 & 1.261 & & \\
\hline Habit formation & $b$ & beta & 0.650 & 0.100 & 0.626 & 0.044 & 0.728 & 0.035 & & \\
\hline Subst. elasticity invest. & $\eta_{i}$ & invgamma & 1.500 & 4.0 & 1.239 & 0.031 & 1.238 & 0.030 & & \\
\hline Subst. elasticity foreign & $\eta_{f}$ & invgamma & 1.500 & 4.0 & 1.577 & 0.204 & 1.794 & 0.318 & & \\
\hline Risk premium & $\tilde{\phi}$ & invgamma & 0.010 & 2.0 & 0.038 & 0.026 & 0.144 & 0.068 & & \\
\hline UIP modification & $\hat{\phi}_{s}$ & beta & 0.500 & 0.15 & 0.493 & 0.067 & 0.488 & 0.029 & & \\
\hline Unit root tech. shock & $\rho_{\mu_{z}}$ & beta & 0.750 & 0.100 & 0.790 & 0.065 & 0.765 & 0.072 & & \\
\hline Stationary tech. shock & $\rho_{\varepsilon}$ & beta & 0.750 & 0.100 & 0.966 & 0.006 & 0.968 & 0.005 & & \\
\hline Invest. spec. tech shock & $\rho_{\Upsilon}$ & beta & 0.750 & 0.100 & 0.750 & 0.077 & 0.719 & 0.067 & & \\
\hline Asymmetric tech. shock & $\rho_{\tilde{\phi}}$ & beta & 0.750 & 0.100 & 0.852 & 0.059 & 0.885 & 0.041 & & \\
\hline Consumption pref. shock & $\rho_{\zeta_{c}}$ & beta & 0.750 & 0.100 & 0.919 & 0.034 & 0.881 & 0.038 & & \\
\hline Labour supply shock & $\rho_{\zeta_{h}}$ & beta & 0.750 & 0.100 & 0.382 & 0.082 & 0.282 & 0.064 & & \\
\hline Risk premium shock & $\rho_{\tilde{z}^{*}}$ & beta & 0.750 & 0.100 & 0.722 & 0.052 & 0.736 & 0.058 & & \\
\hline Unit root tech. shock & $\sigma_{\mu_{\gamma}}$ & invgamma & 0.200 & 2.0 & 0.127 & 0.025 & 0.201 & 0.039 & & \\
\hline Stationary tech. shock & $\sigma_{\varepsilon}^{\mu_{z}}$ & invgamma & 0.700 & 2.0 & 0.457 & 0.051 & 0.516 & 0.054 & & \\
\hline Invest. spec. tech. shock & $\sigma_{\Upsilon}$ & invgamma & 0.200 & 2.0 & 0.441 & 0.069 & 0.470 & 0.065 & & \\
\hline Asymmetric tech. shock & $\epsilon_{\tilde{z}^{*}}$ & invgamma & 0.400 & 2.0 & 0.199 & 0.030 & 0.203 & 0.031 & & \\
\hline Consumption pref. shock & $\sigma_{\zeta_{c}}$ & invgamma & 0.200 & 2.0 & 0.177 & 0.035 & 0.192 & 0.031 & & \\
\hline Labour supply shock & $\sigma_{\zeta_{h}}^{s_{c}}$ & invgamma & 1.000 & 2.0 & 0.470 & 0.051 & 0.511 & 0.053 & & \\
\hline Risk premium shock & $\sigma_{\tilde{\phi}}^{n}$ & invgamma & 0.050 & 2.0 & 0.454 & 0.157 & 0.519 & 0.067 & & \\
\hline Domestic markup shock & $\sigma_{\lambda_{d}}^{\phi}$ & invgamma & 1.000 & 2.0 & 0.656 & 0.064 & 0.667 & 0.068 & & \\
\hline Imp. cons. markup shock & $\sigma_{\lambda_{m, c}}$ & invgamma & 1.000 & 2.0 & 0.838 & 0.081 & 0.841 & 0.084 & & \\
\hline Imp. invest. markup shock & $\sigma_{\lambda_{m, i}, c}$ & invgamma & 1.000 & 2.0 & 1.604 & 0.159 & 1.661 & 0.169 & & \\
\hline Export markup shock & $\sigma_{\lambda_{x}}$ & invgamma & 1.000 & 2.0 & 0.753 & 0.115 & 0.695 & 0.122 & & \\
\hline Interest rate smoothing & $\rho_{R, 1}$ & beta & 0.800 & 0.050 & 0.912 & 0.019 & 0.900 & 0.023 & & \\
\hline Inflation response & $r_{\pi, 1}$ & truncnormal & 1.700 & 0.100 & 1.676 & 0.100 & 1.687 & 0.100 & & \\
\hline Diff. infl response & $r_{\Delta \pi, 1}$ & normal & 0.300 & 0.100 & 0.210 & 0.052 & 0.208 & 0.053 & & \\
\hline Real exch. rate response & $r_{x, 1}$ & normal & 0.000 & 0.050 & -0.042 & 0.032 & -0.053 & 0.036 & & \\
\hline Output response & $r_{y, 1}$ & normal & 0.125 & 0.050 & 0.100 & 0.042 & 0.082 & 0.043 & & \\
\hline Diff. output response & $r_{\Delta y, 1}$ & normal & 0.063 & 0.050 & 0.125 & 0.043 & 0.133 & 0.042 & & \\
\hline Monetary policy shock & $\sigma_{R, 1}$ & invgamma & 0.150 & 2.0 & 0.465 & 0.108 & 0.647 & 0.198 & & \\
\hline Inflation target shock & $\sigma_{\bar{\pi}^{c}, 1}$ & invgamma & 0.050 & 2.0 & 0.372 & 0.061 & 0.360 & 0.059 & & \\
\hline Interest rate smoothing 2 & $\rho_{R, 2}$ & beta & 0.800 & 0.050 & 0.882 & 0.019 & & & & \\
\hline Inflation response 2 & $r_{\pi, 2}$ & truncnormal & 1.700 & 0.100 & 1.697 & 0.097 & & & & \\
\hline Diff. infl response 2 & $r_{\Delta \pi, 2}$ & normal & 0.300 & 0.100 & 0.132 & 0.024 & & & & \\
\hline Real exch. rate response 2 & $r_{x, 2}$ & normal & 0.000 & 0.050 & -0.058 & 0.029 & & & & \\
\hline Output response 2 & $r_{y, 2}$ & normal & 0.125 & 0.050 & 0.081 & 0.040 & & & & \\
\hline Diff. output response 2 & $r_{\Delta y, 2}$ & normal & 0.063 & 0.050 & 0.100 & 0.012 & & & & \\
\hline Monetary policy shock 2 & $\sigma_{R, 2}$ & invgamma & 0.150 & 2.0 & 0.135 & 0.029 & & & & \\
\hline Inflation target shock 2 & $\sigma_{\bar{\pi}^{c}, 2}$ & invgamma & 0.050 & 2.0 & 0.081 & 0.037 & & & & \\
\hline Output stabilization & $\lambda_{y}$ & truncnormal & 0.5 & 100.0 & & & 1.091 & 0.526 & 1.102 & 0.224 \\
\hline Interest rate smoothing & $\lambda_{\Delta i}^{g}$ & truncnormal & 0.2 & 100.0 & & & 0.476 & 0.191 & 0.369 & 0.061 \\
\hline Log marg likelihood laplace & & & & & & & & 1.45 & & \\
\hline
\end{tabular}




\section{Unconditional variances}

As shown in Svensson [19], the model solution satisfies

$$
\begin{aligned}
\tilde{X}_{t+1} & =M \tilde{X}_{t}+\tilde{C} \varepsilon_{t+1}, \\
\tilde{x}_{t} & =F \tilde{X}_{t}
\end{aligned}
$$

where

$$
\tilde{X}_{t} \equiv\left[\begin{array}{c}
X_{t} \\
\Xi_{t-1}
\end{array}\right], \quad \tilde{x}_{t} \equiv\left[\begin{array}{c}
x_{t} \\
i_{t}
\end{array}\right], \quad \tilde{C} \equiv\left[\begin{array}{c}
C \\
0
\end{array}\right]
$$

(note that $\tilde{x}_{t}$ here does not denote the real exchange rate). The variance-covariance matrices of the predetermined variables, $\Sigma_{\tilde{X} \tilde{X}}$, and the forward-looking variables, $\Sigma_{\tilde{x} \tilde{x}}$, therefore satisfy the equations

$$
\begin{aligned}
\Sigma_{\tilde{X} \tilde{X}} & =M \Sigma_{\tilde{X} \tilde{X}} M^{\prime}+\tilde{C} \Sigma_{\varepsilon \varepsilon} \tilde{C}^{\prime}, \\
\Sigma_{\tilde{x} \tilde{x}} & =F \Sigma_{\tilde{X} \tilde{X}} F^{\prime},
\end{aligned}
$$

where $\Sigma_{\varepsilon \varepsilon}$ is the variance-covariance matrix of the i.i.d. shocks $\varepsilon_{t}$.

The solution for the target variables and the observed variables are also functions of the predetermined variables,

$$
\begin{gathered}
Y_{t}=D\left[\begin{array}{c}
X_{t} \\
x_{t} \\
i_{t}
\end{array}\right]=D\left[\begin{array}{cc}
I_{n_{X}} & 0 \\
F
\end{array}\right] \tilde{X}_{t} \equiv \tilde{D} \tilde{X}_{t}, \\
Z_{t}=\bar{D}\left[\begin{array}{c}
X_{t} \\
x_{t} \\
i_{t}
\end{array}\right]+\eta_{t}=\bar{D}\left[\begin{array}{cc}
I_{n_{X}} & 0 \\
F
\end{array}\right] \tilde{X}_{t}+\eta_{t} \equiv \overline{\bar{D}} \tilde{X}_{t}+\eta_{t} .
\end{gathered}
$$

Then their variance-covariance matrices, $\Sigma_{Y Y}$ and $\Sigma_{Z Z}$, can be determined from the variancecovariance matrix of the predetermined variables,

$$
\begin{aligned}
\Sigma_{Y Y} & =\tilde{D} \Sigma_{\tilde{X} \tilde{X}} \tilde{D}^{\prime} \\
\Sigma_{Z Z} & =\overline{\bar{D}} \Sigma_{\tilde{X} \tilde{X}}= \\
& =\Sigma^{\prime}+\Sigma_{\eta \eta}
\end{aligned}
$$

where $\Sigma_{\eta \eta}$ is the variance-covariance matrix of the measurement errors $\eta_{t}$. 


\section{References}

[1] Adam, Klaus, and Roberto Billi (2006), "Optimal Monetary Policy under Commitment with a Zero Bound on Nominal Interest Rates," Journal of Money Credit and Banking 38(7), 18771906.

[2] Adolfson, Malin, Stefan Laséen, Jesper Lindé, and Lars E.O. Svensson (2008), "Optimal Monetary Policy in an Operational Medium-Sized Model," Sveriges Riksbank Working Paper Series No. 225, www.princeton.edu/svensson.

[3] Adolfson, Malin, Stefan Laséen, Jesper Lindé, and Lars E.O. Svensson (2008), "Optimal Monetary Policy in an Operational Medium-Sized Model: Technical Appendix," working paper, www.princeton.edu/svensson.

[4] Adolfson, Malin, Stefan Laséen, Jesper Lindé, and Mattias Villani (2007), "Bayesian Estimation of an Open Economy DSGE Model with Incomplete Pass-Through," Journal of International Economics 72, 481-511.

[5] Adolfson, Malin, Stefan Laséen, Jesper Lindé, and Mattias Villani (2006), "Evaluating an Estimated New Keynesian Small Open Economy Model,” working paper, www.riksbank.se, forthcoming in Journal of Economic Dynamics and Control.

[6] Adolfson, Malin, Stefan Laséen, Jesper Lindé, and Mattias Villani (2007), "RAMSES - a New General Equilibrium Model for Monetary Policy Analysis," Sveriges Riksbank Economic Review, No. 2, 5-40.

[7] Altig, David, Lawrence Christiano, Martin Eichenbaum, and Jesper Lindé (2003), "The Role of Monetary Policy in the Propagation of Technology Shocks," working paper, Northwestern University.

[8] Calvo, Guillermo (1983), "Staggered Prices in a Utility Maximizing Framework," Journal of Monetary Economics 12, 383-398.

[9] Christiano, Lawrence, Martin Eichenbaum, and Charles Evans (2005), "Nominal Rigidities and the Dynamic Effects of a Shock to Monetary Policy," Journal of Political Economy 113(1), $1-45$. 
[10] Del Negro, Marco, Frank Schorfheide, Frank Smets, and Raf Wouters (2007), "On the Fit of New Keynesian Models," Journal of Business and Economic Statistics 25(2), 123-162.

[11] Duarte, Margarida, and Alan Stockman (2005), "Rational Speculation and Exchange Rates," Journal of Monetary Economics 52, 3-29.

[12] Galí, Jordi (2008), Monetary policy, Inflation and the Business Cycle: An Introduction to the New Keynesian Framework, Princeton University Press.

[13] Klein, Paul (2000), "Using the Generalized Schur Form to Solve a Multivariate Linear Rational Expectations Model," Journal of Economic Dynamics and Control 24, 1405-1423.

[14] Kydland, Finn, and Edward Prescott (1982), "Time to Build and Aggregate Fluctuations," Econometrica 50, 1345-1371.

[15] Levine, Paul, Joseph Pearlman, and Bo Yang (2008), "The Credibility Problem Revisited: Thirty Years on from Kydland and Prescott," Review of International Economics, forthcoming.

[16] Rudebusch, Glenn D., and Lars E.O. Svensson (1999), "Policy Rules for Inflation Targeting," in Taylor, John B. (ed.), Monetary Policy Rules, University of Chicago Press, 203-246.

[17] Schmitt-Grohé, Stephanie, and Martín Uribe (2001), "Stabilization Policy and the Costs of Dollarization," Journal of Money, Credit, and Banking 33(2), 482-509.

[18] Smets, Frank, and Raf Wouters (2003), "An Estimated Stochastic Dynamic General Equilibrium Model of the Euro Area," Journal of the European Economic Association, 1(5), 1123-1175.

[19] Svensson, Lars E.O. (2007), "Optimization under Commitment and Discretion, the Recursive Saddlepoint Method, and Targeting Rules and Instrument Rules: Lecture Notes," www.princeton.edu/svensson.

[20] Woodford, Michael (2003b), Interest Rates and Prices, Princeton University Press. 